Article

\title{
Geometric Accuracy of 3D Reality Mesh Utilization for BIM-Based Earthwork Quantity Estimation Workflows
}

\author{
Paulius Kavaliauskas *, Daumantas Židanavičius and Andrius Jurelionis
}

Faculty of Civil Engineering and Architecture, Kaunas University of Technology, 44249 Kaunas, Lithuania; daumantas.zidanavicius@ktu.edu (D.Ž.); andrius.jurelionis@ktu.lt (A.J.)

* Correspondence: pa.kavaliauskas@ktu.edu

Citation: Kavaliauskas, P.;

Židanavičius, D.; Jurelionis, A. Geometric Accuracy of 3D Reality Mesh Utilization for BIM-Based Earthwork Quantity Estimation Workflows. ISPRS Int. J. Geo-Inf. 2021, 10, 399. https://doi.org/10.3390/ ijgi10060399

Academic Editors: Fulvio Rinaudo and Wolfgang Kainz

Received: 20 April 2021

Accepted: 4 June 2021

Published: 9 June 2021

Publisher's Note: MDPI stays neutral with regard to jurisdictional claims in published maps and institutional affiliations.

Copyright: (c) 2021 by the authors. Licensee MDPI, Basel, Switzerland. This article is an open access article distributed under the terms and conditions of the Creative Commons Attribution (CC BY) license (https:// creativecommons.org/licenses/by/ $4.0 /)$.

\begin{abstract}
Current surveying techniques are typically applied to survey the as-is condition of buildings, brownfield sites and infrastructure prior to design. However, within the past decade, these techniques evolved significantly, and their applications can be enhanced by adopting unmanned aerial vehicles (UAVs) for data acquisition, up-to-date software for creating 3D reality mesh, which in turn opens new possibilities for much more efficient construction site surveying and constant updating and process management. In this study the workflows of three UAV-based photogrammetry techniques: Real Time Kinematic (RTK), Post-Processing Kinematic (PPK) and Global Positioning System (GPS) based on control points were analyzed, described, and compared to conventional surveying method with Global Navigation Satellite System (GNSS) receiver. Tests were performed under realistic conditions in 36 ha quarry in Lithuania. The results of the relationship between ground sample distance (GSD) and the comparison of volume measurements under each technique, including conventional method were analyzed. The deviation of data collected on field vs. generated in reality mesh, including ground control points (GCPs) and check points (CHPs) with different configurations, was investigated. The research provides observations on each workflow in the terms of efficiency and reliability for earthwork quantity estimations and explains processing schemes with advanced commercial software tools.
\end{abstract}

Keywords: UAV; photogrammetry; reality mesh; accuracy evaluation; earthwork estimation; reliability

\section{Introduction}

Currently in the world of engineering and surveying, various techniques are used to collect data, including laser scans [1,2], photogrammetry [3,4], total stations [5] and other techniques. While the technology of photogrammetry is not new [6], the software for post-processing and analyzing reality meshes has advanced significantly in recent years. Modern applications have become much more efficient, and the applications of Unmanned Aerial Vehicles (UAVs) helps to efficiently collect data representing various stages of construction sites [7-9], however it requires a lot of computing power to process the collected data. In addition, these technologies are still not widely recognized by professionals who are more confident in conventional survey methods, although these conventional methods are more time-consuming and still are prone to inaccuracies if used for earth quantities calculations.

Point clouds and reality meshes obtained from laser scanning and photogrammetry techniques helped to advance various approaches of processing data from sites, such as automatic building information model (BIM) component extraction and classification [10,11], monitoring of building zones [12], archaeological decision making [13], heritage and landscape applications [14,15], construction and earthwork estimation approaches [16-20], and many more.

The focus of this study is on BIM-based earthworks quantities estimation and the assessment of accuracy obtained by different UAV-based photogrammetry techniques. 
Several studies have been performed on accuracy assessment in this area, where different methods were analyzed to compare point cloud generated data obtained via photogrammetry and laser scanning [21,22], under different camera settings, different values of ground sample distance (GSD) and different number and configuration of ground control points (GCPs) [23-26]. Accuracy analysis results in automatic UAV and terrestrial photogrammetry against different image network configurations, with and without ground control points were presented in [27]. The geometrical accuracy of georeferenced digital surface models obtained from images captured by UAVs and processed by using SfM photogrammetry focused on the number and location of ground control points were analyzed in $[28,29]$. Recent studies have been conducted to evaluate the accuracy of a large-scale topographic map of oblique photogrammetric air survey [30]. The accuracy of the 3D model and the quality of the orthophoto in UAV photogrammetry can be affected by several general conditions, such as camera settings, images resolution, high contrast, uniform surface area, number of control points and correct placement, and much more. A more specific condition that can affect the accuracy of 3D model is the image format and compression level. Several studies on the impact of TIFF format and JPEG image compression on SfM photogrammetry workflows have recently been presented [31,32].

In this research the comparison of the latest UAV-based photogrammetric data acquisition techniques was studied, including Real Time Kinematic (RTK) and Post-Processing Kinematic (PPK) methods. The innovative use of PPK technology has been carried out in conjunction with Propeller marker used as Global Positioning System (GPS) data recording base stations and used with one known point method. Based on previous studies, our research was conducted from a different perspective. Four different methods for earth quantity surveys in construction were analyzed and compared in a single study-from the conventional with GNSS receiver to the latest PPK approach. All four methods were applied using the most commonly used parameters in practice: flight altitude between 70 and $100 \mathrm{~m}$, camera setting set automatically, GCPs were placed incorrectly and in insufficient quantities. The advanced UAV-based methods of data acquisition and post-processing were compared to the GCPs-based method and conventional measurements using RTK Global Navigation Satellite System (GNSS) receiver by comparing 16 stockpiles containing over 10,000 cubic meters of earth. There were no obstacles or moving machinery, but the markers were placed in unfamiliar places with insufficient quantities, which contradicts the recommendations of manufacturers but is close to reality. Therefore, this study simulated a partly realistic environment similar to the construction site. Two separate DJI Phantom 4 RTK and one DJI Phantom 4 PRO UAVs, as well as modern desktop applications and cloud-based platform were used for processing and analysis. Evaluations were carried out by acquiring data from 74 and $100 \mathrm{~m}$ using various configurations of ground control points and check points (CHPs). Optimal altitude, images overlap, and weather conditions for UAV surveys of forest structure were analyzed in [33], where optimal parameters are defined as clear skies, $80 \mathrm{~m}$ altitude, and $80 \%$ side overlap. As shown by several studies $[33,34]$, the methods performed do not have a strong effect of wind speed on the quality of the surveyed data. The aim of this paper is to provide observations of different UAVbased photogrammetric workflows, including efficiency of the whole process, expected accuracy of the model, and reliability of the results. Some studies analyzed and compared the efficiency and accuracy of economical drone mapping [35], RTK/PPK mapping quality prediction and performance [36-39]. Differences between Network Real Time Kinematic, Precise Point Positioning and static mode were tested in [40]. This paper also looks into comparison of the results obtained with the previously published studies in the field.

Modern photo-based surveys are processed by automatically identifying and matching appropriate features in the images. Computer vision algorithms have capabilities to extract features from a set of overlapping images. Structure-from-Motion (SfM) technique is used in most modern photogrammetric software, which utilizes multiple 2D images to reconstruct a 3D scene or object, as a point cloud similar to Light Detection and Ranging (LiDAR). Applications using SfM methods can produce orthophotograph mosaics, 3D point 
clouds, and Digital Elevation Models (DEMs). Advances in computer hardware, digital cameras and UAVs have made these techniques possible for a wide range of users to generate 3D models from the images. SfM technique has been demonstrated as highly promising in several studies [41-46]. Based on that, the transition towards automated processes and photogrammetry-based techniques are highly important, although more detailed analysis and software comparison was out of scope of this particular study.

Building on the previously published studies in this area, this paper looks into the performance and reliability of results obtained using three different UAV-based photogrammetric techniques and the comparison of accuracy between these methods and the conventional survey method using GNSS receiver.

\section{Methods}

\subsection{Data Acquisition}

The testing site selected for this study is a quarry in Lithuania, covering the area of 36 ha. The view of the site is provided in Figure 1. Ground-level survey was performed using a Trimble SPS985 GNSS receiver with RTK fixed precision type. A description of this method and details of measurement precision are provided in Section 2.1.1. The drone flights were carried out from different heights: 100 and $74 \mathrm{~m}$. The conventional UAVground control based approach was compared with the advanced PPK one known point method. In addition, smaller-scale tests with RTK and under winter conditions with PPK methods were performed. The UAV-based RTK approach is further described in Section 2.1.2., and PPK in Section 2.1.3. Separate UAVs were used for each method: two DJI Phantom 4 RTKs and one DJI Phantom 4 PRO. These drones were selected for the study as quite common and widely used in the industry for mapping purposes. Before the flights, 11 markers were placed and measured in the area to determine GCPs and CHPs in order to scale and check the accuracy of the model (Figure 2a). The markers were manufactured of $60 \times 60 \mathrm{~cm}$ marine plywood and painted in black and white squares (Figure $2 b$ ). Propeller AeroPoints 1.0 base stations were used as markers for the PPK method, along with additional self-made plywood boards, which were used as check points. (Figure 2c).

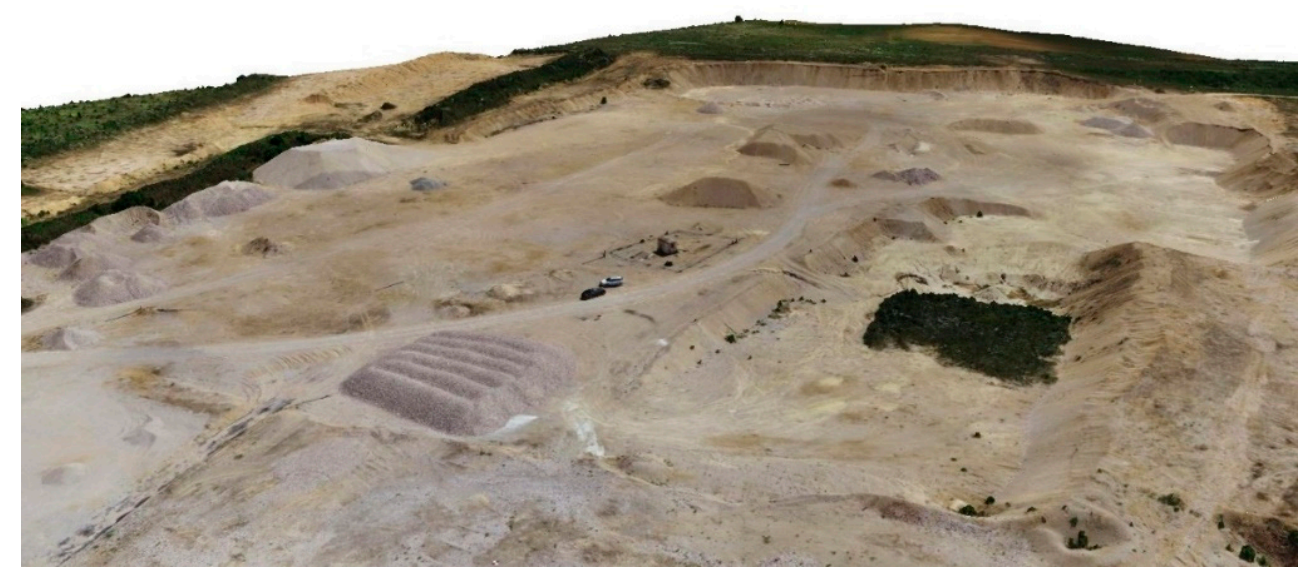

Figure 1. The view of the site-reality mesh model post-processed with ContextCapture tool. 


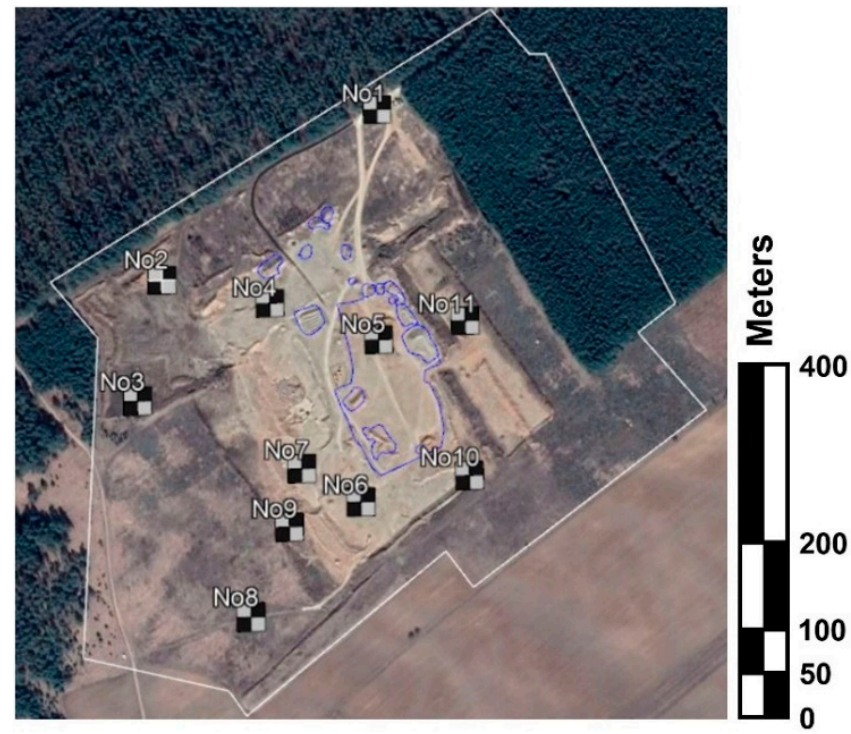

(a)

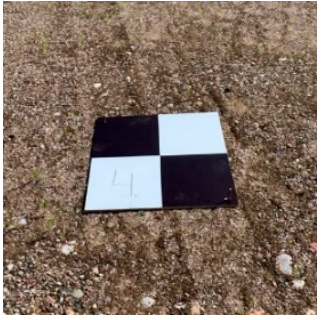

(b)

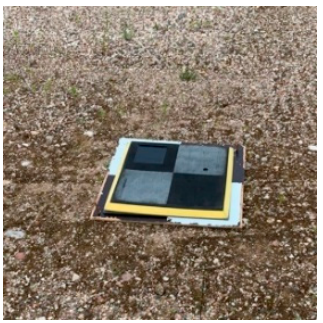

(c)

Figure 2. Site scheme and equipment: (a) area boundaries and markers with control points. The blue boundaries show the areas of conventional Global Navigation Satellite System (GNSS) surveys of stockpiles, (b) ordinary self-made marker and (c) Propeller AeroPoint 1.0 marker.

The research methodology consists of seven datasets, which include a conventional ground-level survey with a GNSS receiver and three UAV-based photogrammetric approaches, including data acquisition with a GSD value of 2.03 and $2.74 \mathrm{~cm} / \mathrm{px}$. During data acquisition, stockpiles were not changed, and the quarry was inactive. GNSS receiver data was processed using Civil3D engineering software. Datasets, including GCPs-based and RTK data, were processed using desktop Bentley ContextCapture software and analyzed using Bentley Descartes. Post-Processing Kinematic datasets were processed and analyzed using cloud-based Trimble Stratus and Propeller platform. The research methodology scheme is shown in Figure 3.

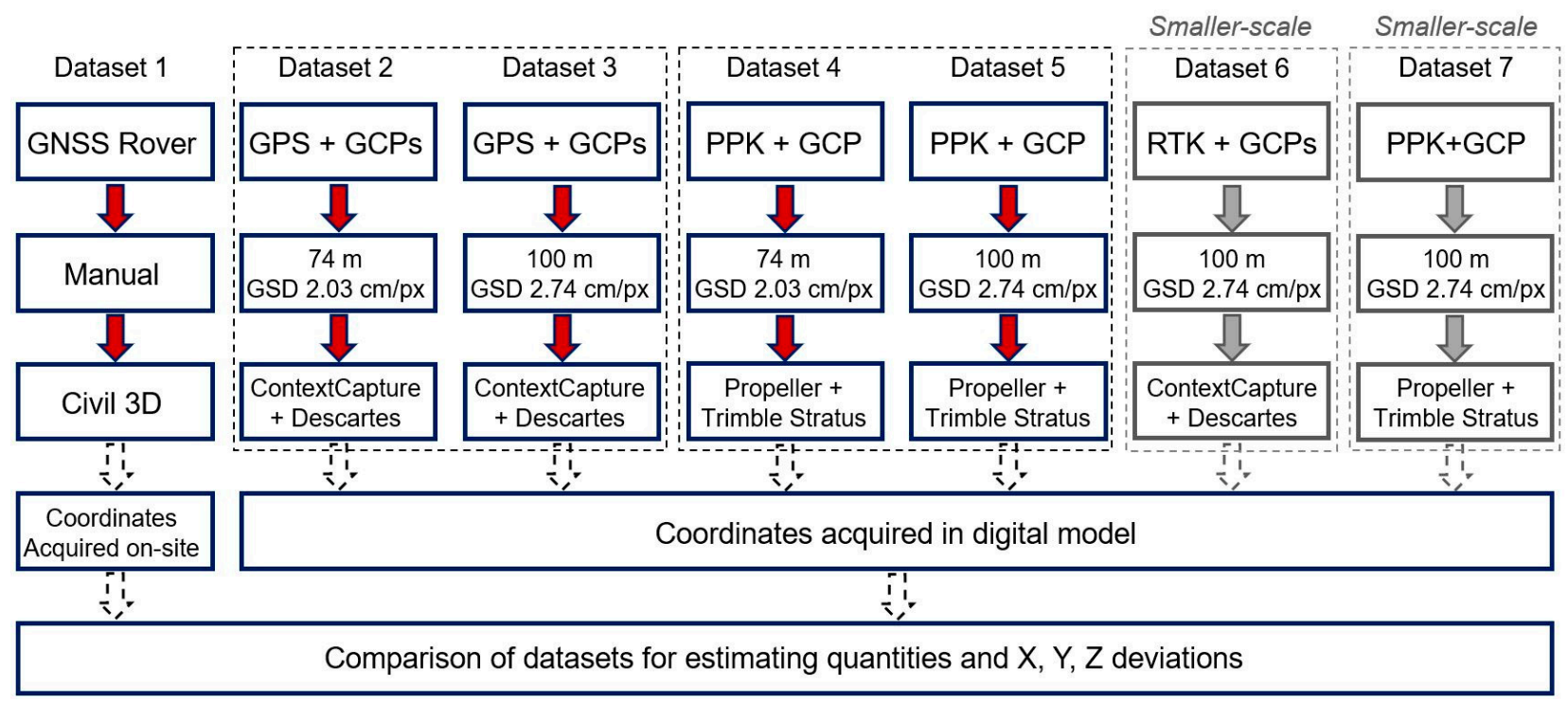

Figure 3. Methodology for Unmanned Aerial Vehicle (UAV)-based automated stockpile volumes calculation accuracy assessment: The coordinates obtained locally with Trimble GNSS receiver were compared with the known points of the digital model. The volumes of stockpiles were calculated and compared between all datasets. 
DJI Phantom 4 RTK drones are quite common in the industry for mapping and surveying purposes, but about three times cheaper DJI Phantom 4 PROs are also used. Compared to DJI Phantom 4 RTK, the aircraft does not have an integrated GNSS RTK antenna onboard, which allows the system to directly tag the positioning coordinates, which should theoretically mean a loss of accuracy compared to DJI Phantom 4 RTK. The flights were conducted in sunny summer conditions with clear skies, despite the wind speed. The flight plan was based on 2D photogrammetry nadir pattern (Figure $4 \mathrm{a}, \mathrm{b}$ ), with $80 \%$ front overlap, $70 \%$ side overlap and $5.8 \mathrm{~m} / \mathrm{s}$ max flight speed of the aircraft. Other settings: gimbal angle $-90^{\circ}$, photo ratio 3:2 and distance shooting mode. The GSD of $2.74 \mathrm{~cm} / \mathrm{px}$ was obtained capturing images at $100 \mathrm{~m}$ height with DJI Phantom 4 PRO and RTK UAVs with originally built-in cameras with image width 5472 px, image height 3648 px, sensor width $13.2 \mathrm{~mm}$, sensor height $8 \mathrm{~mm}$ and focal length $8.8 \mathrm{~mm}$ settings. With the analogical settings the GSD of $2.03 \mathrm{~cm} / \mathrm{px}$ was obtained when flying at $74 \mathrm{~m}$ height.

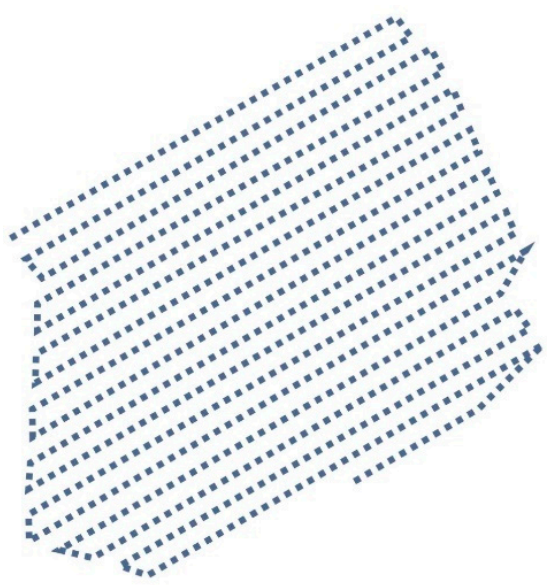

(a)

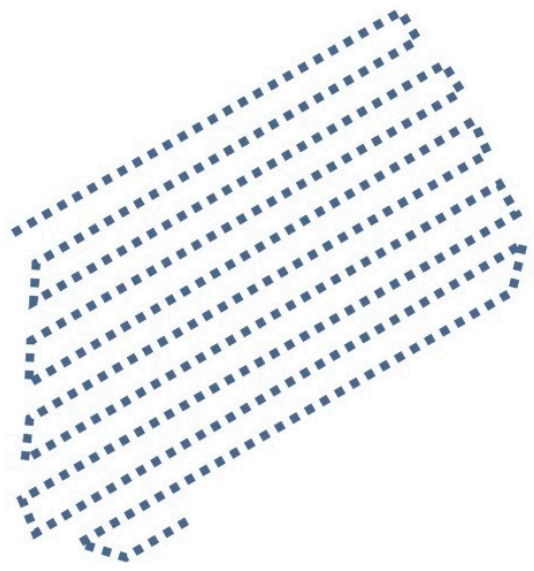

(b)

Figure 4. Flight schemes: (a) flight $74 \mathrm{~m}$ above the ground, (b) flight $100 \mathrm{~m}$ above the ground.

\subsubsection{Conventional Approach}

Our conventional surveying method was based on manual measurements with a Trimble SPS989 RTK GNSS receiver, which uses Lithuanian Positioning System (LitPOS). LitPOS is a Global Navigation Satellite System infrastructure for Lithuania. It combines a network of base GNSS stations with dedicated communication channels and appropriate hardware and software. LitPOS permanent reference stations provide data for real-time and post-processing applications and cover the whole territory of Lithuania [47]. This method was used for setting up known points and estimating the quantities of stockpiles volumes for later comparison with UAV-based photogrammetric approaches. A total of 1108 data points were collected on site and 16 stockpiles were measured and processed with Civil 3D software for volume calculations (Figure 5). On the flat surface, points were measured at distances ranging from 10 to $15 \mathrm{~m}$, and on stockpiles at distances ranging from 1 to $5 \mathrm{~m}$, depending on curvatures. It took approximately one working day for a professional surveyor to collect this amount of data. It took another half day to process the data and to calculate the volumes. A total 2D area of 5549.55 square meters and 10,532.21 cubic meters of earth volume was evaluated. The measurement of each stockpile is reported in Table 1. 


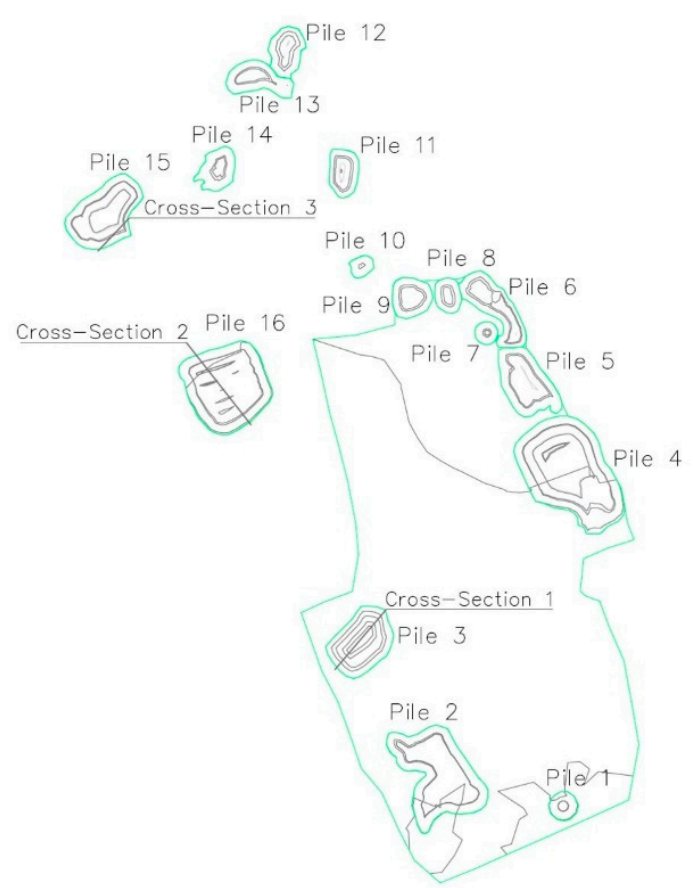

Figure 5. Data acquired with Trimble GNSS receiver. Marked positions of three random cross-sections.

Table 1. Summary of stockpiles quantities acquired by means of conventional method.

\begin{tabular}{|c|c|c|}
\hline Name & 2d Area (Sq. m) & $\operatorname{Net}(\mathrm{Cu} . \mathrm{m})$ \\
\hline Pile 1 & 87.66 & 91.95 \\
\hline Pile 2 & 790.59 & 1407.86 \\
\hline Pile 3 & 427.14 & 832.19 \\
\hline Pile 4 & 1107.03 & 3046.91 \\
\hline Pile 5 & 390.47 & 623.28 \\
\hline Pile 6 & 316.83 & 475.5 \\
\hline Pile 7 & 55.60 & 48.22 \\
\hline Pile 8 & 102.60 & 115.7 \\
\hline Pile 9 & 177.34 & 242.96 \\
\hline Pile 10 & 53.27 & 36.21 \\
\hline Pile 11 & 160.91 & 255.4 \\
\hline Pile 12 & 184.48 & 228.59 \\
\hline Pile 13 & 217.71 & 255.57 \\
\hline Pile 14 & 166.90 & 175.31 \\
\hline Pile 15 & 493.98 & 1185.39 \\
\hline Pile 16 & 817.04 & 1511.13 \\
\hline Total & 5549.55 & $10,532.18$ \\
\hline
\end{tabular}

The method of measurements was taken from real industrial surveying application which is used in practice for earthworks quantity estimations. Although robotic total stations or tacheometers can be used for more accurate results, but our purpose was to simulate realistic situation of earthworks survey in the field based on real environment applications, where tacheometers are rarely used for this kind of works. A set of ground control points was measured and determined using a GNSS receiver. The precision of the measurements and the measurement information of the markers are provided in Table 2. Horizontal measurements were taken in the European Petroleum Survey Group (EPSG) projection 3346-Lithuanian Coordinate System (LKS94) and vertical measurements in the Lithuanian State Elevation System (LAS07) used with Lithuanian Territorial Geoid Model (LIT15G). The coordinates are also given in the World Geodetic System 1984 format. In reality, there are usually many obstacles and moving traffic on site, making it impossible 
to place markers in the corners, edges, and in the middle of the area, as recommended by the manufacturers. For those reasons, the markers were arranged randomly to analyze different layout configurations.

Table 2. Control points measurement information. Device—-Trimble SPS985. Precision type-Real Time Kinematic (RTK) Fixed.

\begin{tabular}{|c|c|c|c|c|c|c|c|c|}
\hline CP No & $\begin{array}{l}\text { Northing, } \\
\text { (Meters) }\end{array}$ & $\begin{array}{l}\text { Easting, } \\
\text { (Meters) }\end{array}$ & $\begin{array}{l}\text { Elevation, } \\
\text { (Meters) }\end{array}$ & $\begin{array}{l}\text { H. Precision } \\
\text { (Meters) }\end{array}$ & $\begin{array}{l}\text { V. Precision } \\
\text { (Meters) }\end{array}$ & $\begin{array}{c}\text { HA/Lat } \\
\text { (Deg.Min.Sec.) }\end{array}$ & $\begin{array}{c}\text { VA/Long } \\
\text { (Deg.Min.Sec.) }\end{array}$ & $\begin{array}{l}\text { SD/WGSHt } \\
\text { (Meters) }\end{array}$ \\
\hline 1 & $6,050,236.702$ & $556,234.258$ & 162.661 & 0.008 & 0.013 & 54.35 .0814518 & 24.52 .1194348 & 187.901 \\
\hline 2 & $6,050,043.436$ & $555,982.149$ & 159.556 & 0.008 & 0.013 & 54.35 .0199501 & 24.51 .5777158 & 184.801 \\
\hline 3 & $6,049,904.339$ & $555,953.424$ & 159.463 & 0.008 & 0.014 & 54.34 .5750764 & 24.51 .5607667 & 184.71 \\
\hline 4 & $6,050,013.152$ & $556,105.802$ & 157.799 & 0.009 & 0.015 & 54.35 .0096623 & 24.52 .0463640 & 183.043 \\
\hline 5 & $6,049,966.717$ & $556,230.278$ & 156.111 & 0.009 & 0.016 & 54.34 .5941459 & 24.52 .1153583 & 181.355 \\
\hline 6 & $6,049,781.284$ & $556,206.66$ & 155.857 & 0.01 & 0.018 & 54.34 .5342656 & 24.52 .1009295 & 181.104 \\
\hline 7 & $6,049,821.187$ & $556,140.183$ & 152.67 & 0.01 & 0.018 & 54.34 .5474372 & 24.52 .0641886 & 177.917 \\
\hline 8 & $6,049,656.291$ & $556,080.627$ & 157.837 & 0.01 & 0.017 & 54.34 .4943427 & 24.52 .0298929 & 183.087 \\
\hline 9 & $6,049,755.716$ & $556,125.198$ & 157.208 & 0.011 & 0.016 & 54.34 .5263218 & 24.52 .0553941 & 182.456 \\
\hline 10 & $6,049,807.246$ & $556,330.669$ & 158.154 & 0.01 & 0.014 & 54.34 .5421658 & 24.52 .1701592 & 183.399 \\
\hline 11 & $6,049,985.528$ & $556,330.097$ & 155.408 & 0.01 & 0.015 & 54.34 .5998302 & 24.52.1710714 & 180.651 \\
\hline
\end{tabular}

\subsubsection{RTK Based Approach}

Real-time kinematic processes on drone recorded GPS information and geotags images as they are captured during the flight. The GPS location is recorded for the center of the image. However, on-UAV GPS units are not very accurate. They can have deviations on average of 3-9 $\mathrm{m}$ from the actual X, Y, Z location of a feature in the real environment. With RTK, the position of the UAV relative to the base is determined accurately due to a passive base station on the ground that sends raw GPS data to the UAV. On-board GPS then collects this information to correct the position. RTK UAV has to keep a connection with the base station the entire time of data gathering. While this method is highly efficient, the loss of signal when turning, likely due to antenna orientation, can make some data unreliable. These risks can be mitigated by ensuring a stable radio link to receive base station data, which is processed during the flight.

In this study, when flying RTK at an altitude of $74 \mathrm{~m}$, the RTK signal was lost and the data became unreliable, so it was exempted from further post-processing. Nevertheless, the flight in a $100 \mathrm{~m}$ height was suitable for further analysis and comparison to the rest of the surveys. Retaking the $74 \mathrm{~m}$ height flight data was not possible due to the changes in the testing site. As a base station, the radio controller with LitPOS network RTK service was used. The network of permanent reference GNSS stations provides data for both real-time and post-processing applications, where GNSS satellite error signals are calculated and eliminated in real time. This technology is based on the fact, that GNSS reference stations are installed at points on the ground, the coordinates of which are known exactly in the required coordinate system. The measurement data of reference stations is summarized, systematized, and GNSS corrections are broadcasted via telemetry communication channels. LitPOS stations cover the whole territory of Lithuania with total number of 26 LitPOS GNSS stations.

\subsubsection{PPK Based Approach}

In traditional drone surveying workflow, a sufficient number of known points is needed to verify and pin UAV imagery to the ground, because its position in the sky is not accurately geotagged and the accuracy is ensured by means of the ground control points. With PPK, the UAV geotags X, Y, Z coordinates to each image based on on-board GPS unit and at the same time a base on the ground is also recording positional information with more accurate triangulation (Figure 6). 


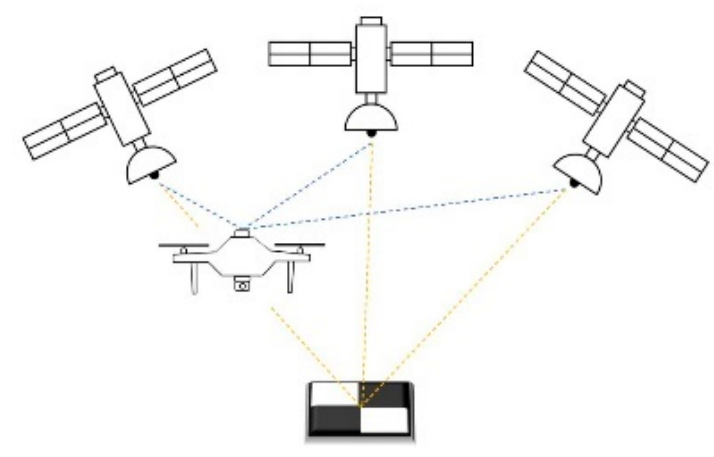

Figure 6. A conceptual scheme of UAV and a base record Global Positioning System (GPS) information.

DJI Phantom 4 RTK drone was used with turned off RTK function, and with 5 AeroPoints additionally used as base stations for GPS data recording. The timestamps were given for each image, captured during the flight when a camera shutter was triggered. After the flight, both sets of GPS data were matched up using timestamps, post-processed to recreate the precise flight path, and on-board GPS data was overwritten, giving precise geotags for the imagery. We conducted a 1 known point method, which means that we set up one AeroPoint as a GCP with known coordinates for the whole area and other 4 markers were used as check points for additional accuracy assessment (Figure 7a). To make GPS signal clear, the AeroPoints were placed on flat surface in an open area of $15^{\circ}$ without obstacles from the ground around the base stations. Before flying the drone, the AeroPoints were in place for about $15 \mathrm{~min}$ and were collected after $45 \mathrm{~min}$ from the time when they were placed. With AeroPoints 1.0 the UAV has to be continuously in the air for at least 10 min before returning after mission. The two datasets consisted of 3 flights which were over 10 min each. Flights' information is provided in Tables 3 and 4 and Figure 8a,b. To compare the efficiency of data acquisition using ground-level survey and UAV-based approaches other than preparation time, data collection from approximately 15 square meters using a GNSS receiver took $1 \mathrm{~min}$, while 24,000 and 9730 square meters of data were obtained during the same time using UAV-based approaches. Additional smaller-scale PPK flight was performed with $1 \mathrm{GCP}$ and 4 check points under winter conditions to observe the influence of weather conditions on the accuracy results (Figure $7 \mathrm{~b}$ ).

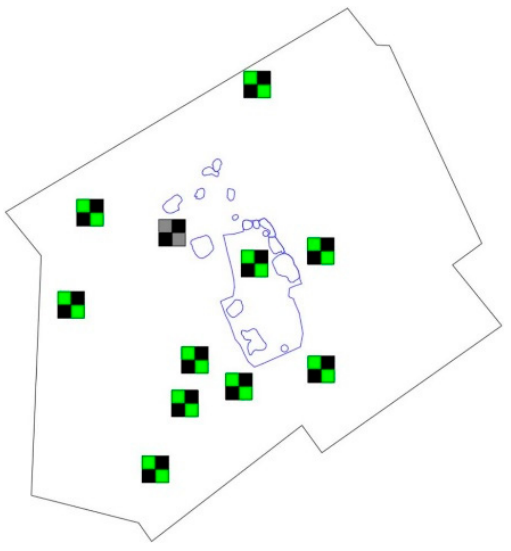

(a)

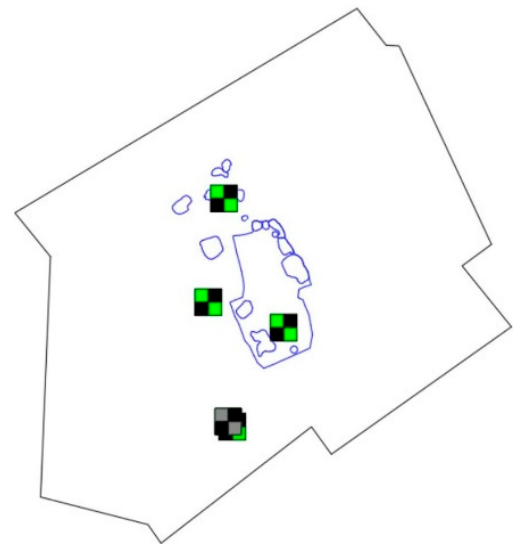

(b)

Figure 7. Post-Processing Kinematic (PPK) survey control points configurations in a test site: (a) 1 known point +10 check points (CHPs), (b) 1 known point +4 CHPs. 
Table 3. $74 \mathrm{~m}$ flight Post-Processing Kinematic (PPK) image tags.

\begin{tabular}{cccccc}
\hline Flight & Start & End & Images & Flight Duration & GPS Quality \\
\hline Flight 1 & 9 July 2020, 12:29 PM & 9 July 2020, 12:48 PM & 450 & $19 \mathrm{~min}$ & $100.00 \%$ \\
Flight 2 & 9 July 2020, 12:51 PM & 9 July 2020, 1:09 PM & 433 & 18 min & $100.00 \%$ \\
\hline
\end{tabular}

Table 4. $100 \mathrm{~m}$ flight PPK image tags.

\begin{tabular}{cccccc}
\hline Flight & Start & End & Images & Flight Duration & GPS Quality \\
\hline Flight 1 & 9 July $2020,1: 19$ PM & 9 July $2020,1: 36$ PM & 392 & 17 min & $100.00 \%$ \\
\hline
\end{tabular}

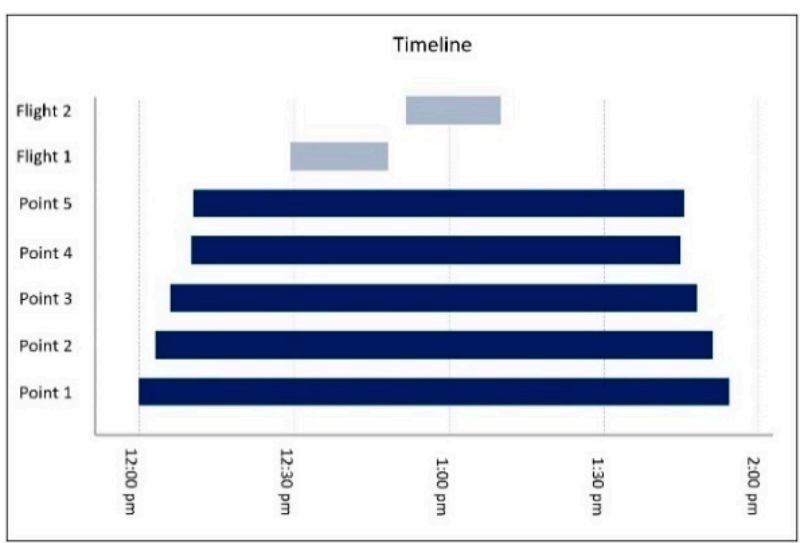

(a)

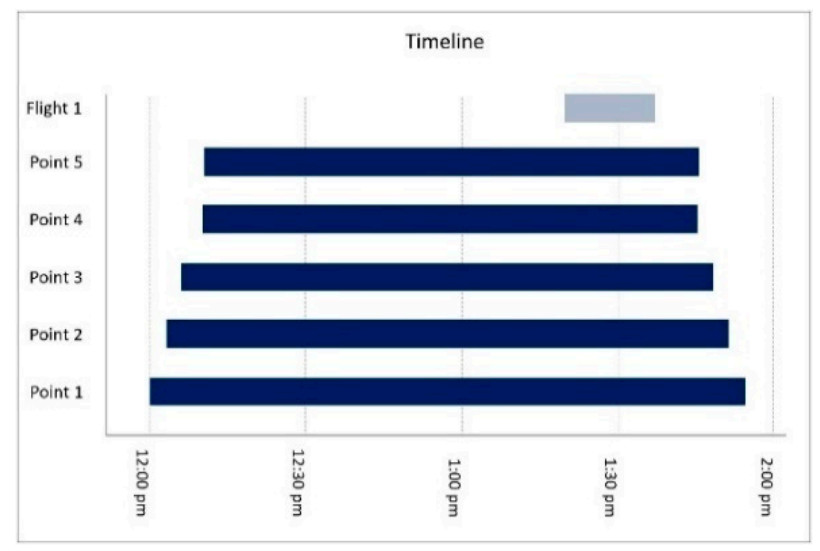

(b)

Figure 8. Timelines of flights and GPS data acquisition with AeroPoints: (a) $74 \mathrm{~m}$ flights and (b) $100 \mathrm{~m}$ flight.

\subsection{Data Processing}

In this research different methodologies and modern software tools were used to process and analyze the data. For processing the data based on Trimble GNSS receiver measurements Autodesk Civil 3D 2021 software was used. All gathered data was imported into the software and Triangulated Irregular Network (TIN) surfaces were created and analyzed with Volume Dashboard tool. This method is still widely used in the construction industry for earth quantities surveys. The obtained results were further imported to Descartes and Trimble Stratus platforms for comparison with the PPK based method. Visualization is provided in Figure 9a,b.

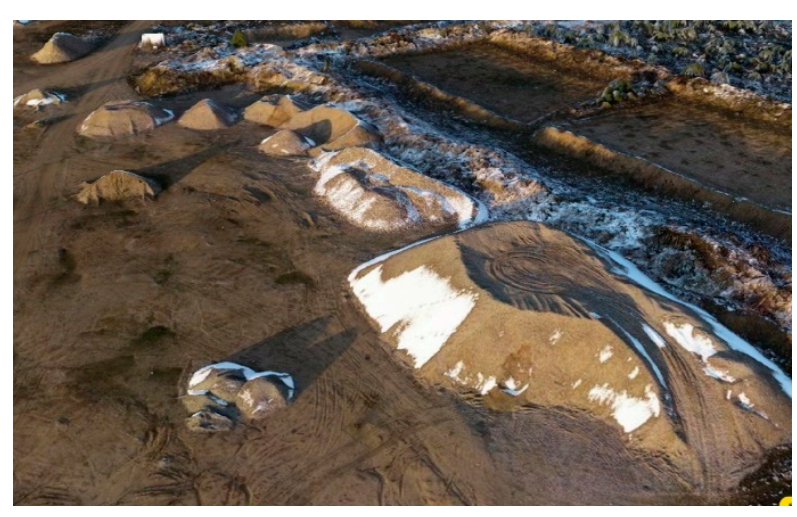

(a)

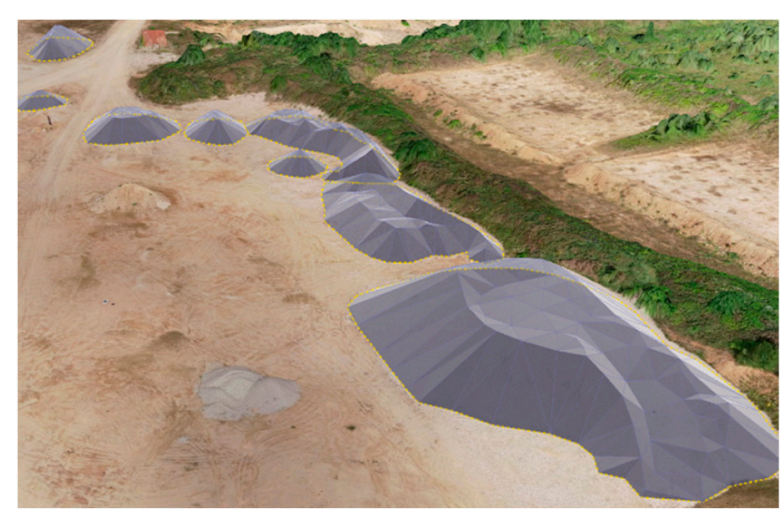

(b)

Figure 9. Visualization of Triangulated Irregular Network (TIN) surfaces imported to Trimble Stratus under different conditions: (a) reality mesh, $(\mathbf{b})$ reality mesh with TIN surfaces. 
Trimble stratus works together with Propeller which is a cloud-based data visualization and analytics platform. To upload images, PPK data and configure settings were relatively simple. We used five AeroPoints 1.0 for GPS data recording. For data processing in PPK methodology one known point method was used, which means that X, Y, Z coordinates were provided manually for only one control point. After data upload, the two sets from the UAV and AeroPoints were matched up using the image stamps, and GPS data then was corrected, advanced algorithms processed the data and analyzed its quality. Our known point set as the control point was number 4 . The remaining 10 points were used as check points for assessing the accuracy. The quantities of stockpiles were calculated by creating the measurements from the boundaries imported from Civil 3D survey, as well some random cross-sections were analyzed comparing conventional survey design to obtained reality mesh, which is shown in Figure 10.

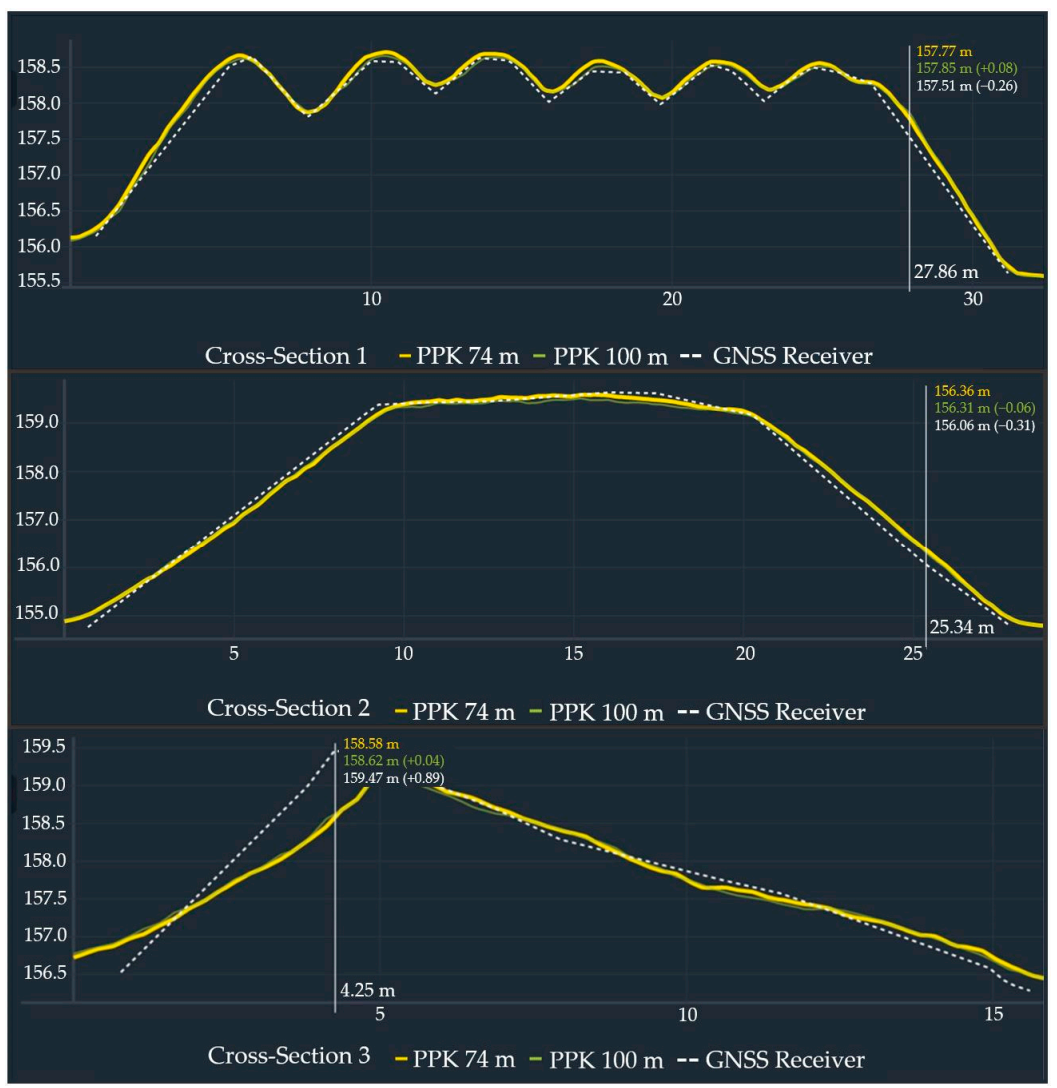

Figure 10. Cross-sections of the three selected cross sections obtained through PPK surveys and Civil 3D design.

In selected cross-sections it is visible that the differences between two reality meshes obtained from 74 and $100 \mathrm{~m}$ were about $0.04-0.08 \mathrm{~m}$ in some parts. Compared to the survey design imported from Civil 3D, the differences in some parts of the cross-sections were as high as $0.26-0.89 \mathrm{~m}$. This is because manual measurements were taken every meter or several meters.

Ground control-based UAV survey datasets were processed in desktop software Bentley ContextCapture 10.17.00.39 and analyzed in Bentley Descartes 10.07.00.15. Processing was done in three configurations of GCPs which are shown in Figure 11a-c with default setting of triangulation and reconstruction. The software itself has more capabilities but processing and analysis requires much more knowledge and experience compared to Trimble Stratus Propeller platform. RTK survey data was processed and analyzed in the same Bentley software tools. As GCPs-based method requires a sufficient number of control points, three configurations of 5,6 and 8 GCPs were set, leaving the rest of the points for 
the accuracy assessment. The optimal number of GCPs in this study case was 6 , as 5 and 8 GCPs configurations gave abnormal values comparing to ground-level survey. For this reason, the starting number of GCPs using RTK technique was 5 and in the second configuration the number was reduced to 3 GCPs. (Figure 12a,b). The software does not allow to select less than 3 GCPs but data can be processed using metadata only.

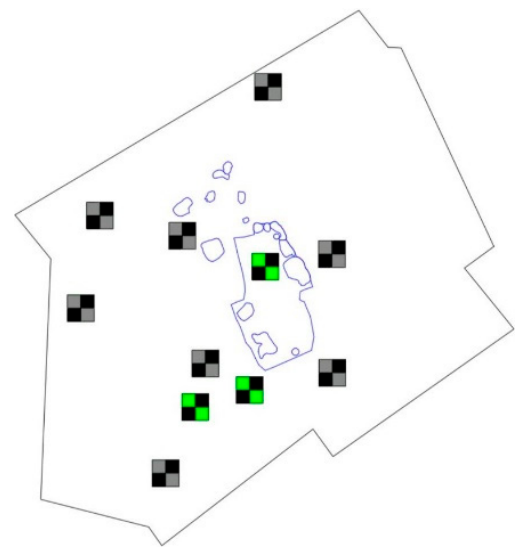

(a)

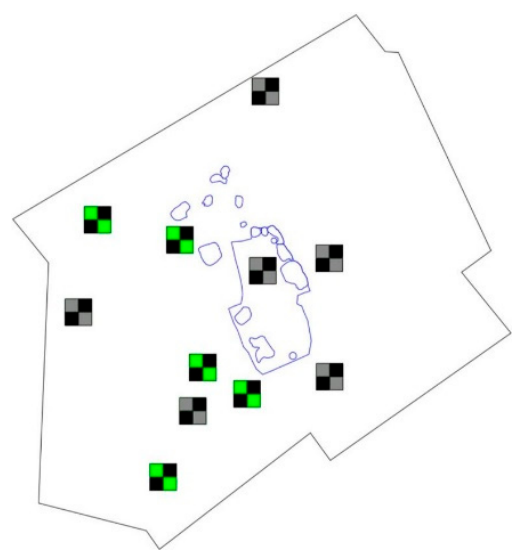

(b)

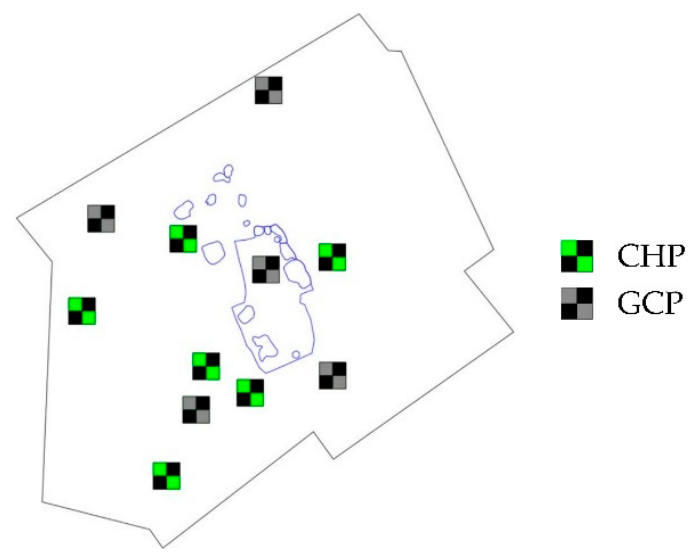

(c)

Figure 11. Ground control points (GCPs)-based survey control points configurations in the testing site: (a) $8 \mathrm{GCP}+3 \mathrm{CHPs}$, (b) 6 GCPs + 5 CHPs, (c) 5 GCPs +6 CHPs.

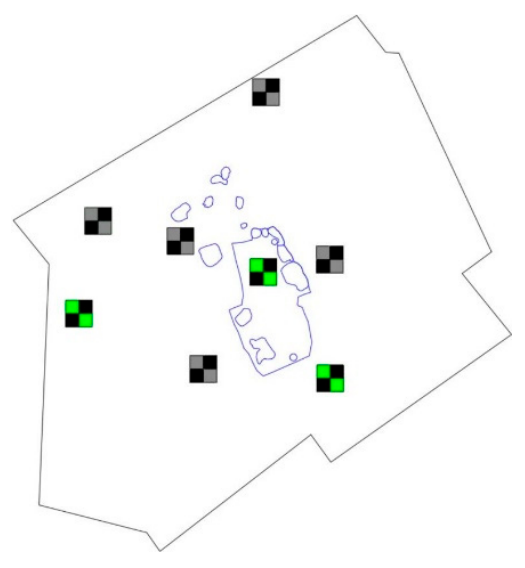

(a)

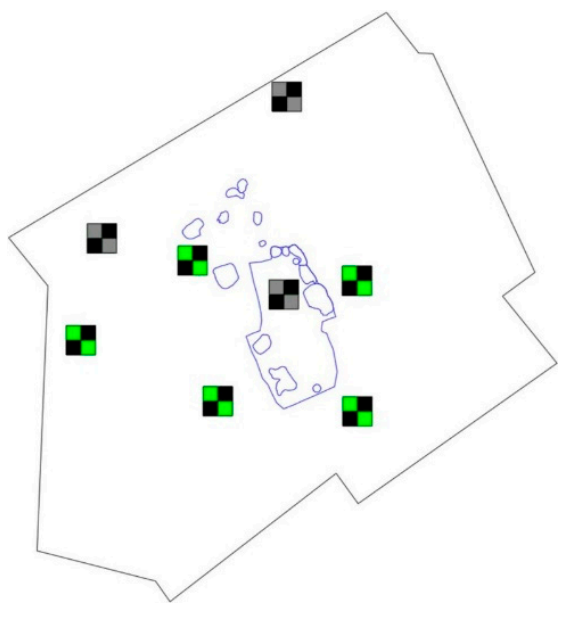

(b)

Figure 12. Real Time Kinematic (RTK) survey control points configurations in the testing site: (a) 5 GCP +3 CHPs, (b) 3 GCPs +5 CHPs.

The accuracy of control points was evaluated by performing manual measurements from the surface of reality mesh (Tables S1-S6 in the Supplementary Materials illustrate the coordinates of the control points obtained from the reality mesh). The example is provided in Figure 13, where the centers of the images show $X$ and $Y$ coordinates acquired on site with GNSS receiver. The software processing reports in many cases provide different results from what can be measured manually using cursor in desktop application. From the practical point of view the accuracy of points was assessed by using cursor. Considering the resolution of images, $X$ and $Y$ values may have not been estimated with high precision, therefore the main focus of accuracy assessment was intended on volume and $Z$ values analysis. To measure $Z$ values, the same manual method by using cursor as mentioned before was used. Not depending on the images' resolution, for height measurements this type of evaluation was reliable. 


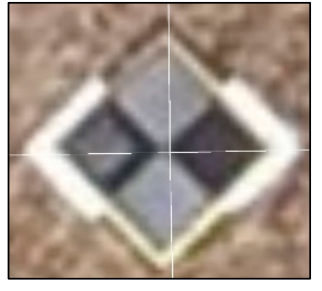

(a)

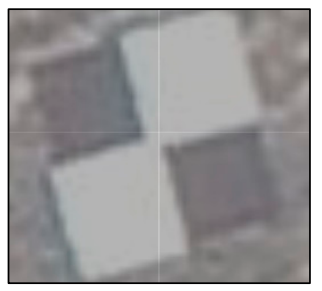

(d)

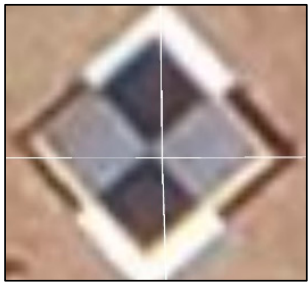

(b)

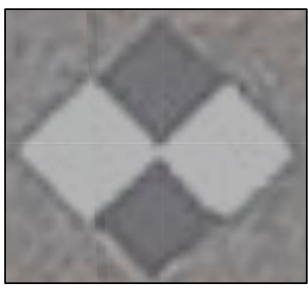

(e)

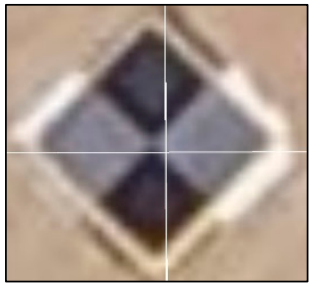

(c)

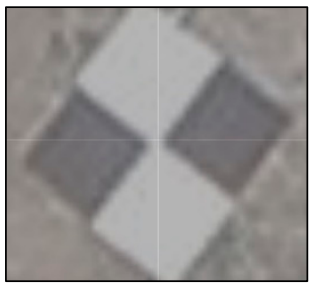

(f)

Figure 13. Example of $X$ and $Y$ measurements in the reality mesh model. The centers across the images show GNSS receiver coordinates acquired on site-in the Trimble Stratus platform: (a) point no. 4 , (b) point no. 5, (c) point no. 6; in Bentley Descartes application with mesh transparency set to $50 \%$ : (d) point no. 2, (e) point no. 4, (f) point no. 9.

Some of the stockpiles had vegetation in some places that photogrammetry cannot handle with high enough precision. To mitigate the inaccuracies related to this, an average height was measured from both ends of the surface without vegetation. Therefore, vegetation was disregarded in further calculations of stockpile volumes.

\section{Results and Discussion}

The results of the study are presented in the following way: Section 3.1. looks in stockpiles volume estimation and comparison, Section 3.2. analyzes the results of ground control points and check points, focusing on $\mathrm{Z}$ values. In Section 3.3. the main limitations of UAV-based photogrammetric methods are described.

Recent study analyzed the accuracy assessment by using different configurations of GCPs and camera settings and compared different software packages and processing schemes [23]. The study based on variation of 72 GCPs was conducted in 17.64 ha area [24]. GNSS and UAV-based photogrammetry results [48], analysis of quality assessment of UAV flights with RKT positioning [49], research of coastal mapping using DJI Phantom 4RTK in PPK mode [37] were presented in recent years. Evaluation of software accuracy, advantages and disadvantages were outside the scope of this study, the software was selected modern, in PPK case adapted to the particular method. There are several studies of software comparison of the most popular SfM tools: Bentley ContextCapture, Agisoft Metashape, Reality Capture, Pix4D, and others, presented in the scientific field [23,50,51].

\subsection{Volume Estimation Analysis}

A total of 16 individual stockpiles containing more than 10,000 cubic meters of earth were assessed for quantity, efficiency, and accuracy. Firstly, the ground-level survey was conducted with Trimble GNSS receiver and processed in Civil 3D software. Then the data was captured using three different UAV-based photogrammetric approaches. GCPs-based and RTK data from UAVs was processed using ContextCapture and analyzed in Descartes. PPK data was processed using Trimble Stratus powered by Propeller platform. The results from Civil 3D were imported into photogrammetric reality mesh models for comparisons. Exactly the same measurements' boundaries were used in all cases (Figures S1-S3 in the Supplementary Materials show the examples of the boundaries used for stockpiles volume comparison). Ground-level survey data consisted of 1108 points and of 5549.55 square 
meters of surface, and it took about one day to measure. Meanwhile, it took $37 \mathrm{~min}$ to fly at $74 \mathrm{~m}$ and $17 \mathrm{~min}$ when flew at $100 \mathrm{~m}$ to get data with millions of points, and they covered an entire area of $36 \mathrm{ha}$. Processing time was approximately from 4 to $10 \mathrm{~h}$, regardless of which method was used. Bentley applications required more time and specific knowledge, but the visual output is much better with more scope for further analysis. GCPs workflow demands about 10 times more work on the site each time, placing the GCPs in the right positions and surveying them compared to RTK or PPK methods.

The quantities of stockpiles are reported in Table 5. The highest amounts were obtained using a ground-level survey with a GNSS receiver. It is almost impossible to calculate the exact amount of the earth, but the inaccuracies are visible in the random cross-sections demonstrated in Section 2.2. The results of 16 stockpiles are provided in Figure 14.

Table 5. 16 stockpiles volume calculations results.

\begin{tabular}{|c|c|c|c|c|c|}
\hline \multirow{3}{*}{ Stockpile Number } & \multicolumn{5}{|c|}{ Stockpile Volumes in Cubic Meters Obtained through Each Method } \\
\hline & \multirow{2}{*}{$\begin{array}{c}\text { GNSS Receiver } \\
\text { Ground Level }\end{array}$} & \multicolumn{2}{|c|}{ PPK } & \multicolumn{2}{|c|}{6 GCPs-Based } \\
\hline & & 74 m Height & $100 \mathrm{~m}$ Height & 74 m Height & $100 \mathrm{~m}$ Height \\
\hline 1 & 91.95 & 96.95 & 94.57 & 95.09 & 94.95 \\
\hline 2 & 1407.86 & 1285 & 1254 & 1280.17 & 1273.18 \\
\hline 3 & 832.19 & 791 & 775 & 797.65 & 791.79 \\
\hline 4 & 3046.91 & 3210 & 3187 & 3119.22 & 3003.53 \\
\hline 5 & 623.28 & 598 & 582 & 650.09 & 639.56 \\
\hline 6 & 475.5 & 421 & 413 & 430.66 & 411.46 \\
\hline 7 & 48.22 & 51.65 & 49.17 & 50.8 & 49.1 \\
\hline 8 & 115.73 & 117 & 114 & 114.65 & 114.44 \\
\hline 9 & 242.96 & 239 & 236 & 236.13 & 229 \\
\hline 10 & 36.21 & 35.15 & 32.82 & 36.35 & 36 \\
\hline 11 & 255.4 & 236 & 230 & 226.56 & 223.05 \\
\hline 12 & 228.59 & 210 & 194 & 219.38 & 219.19 \\
\hline 13 & 255.57 & 266 & 266 & 267.28 & 253.86 \\
\hline 14 & 175.31 & 157 & 153 & 161.34 & 154.25 \\
\hline 15 & 1185.39 & 1101 & 1094 & 1060.42 & 1053.92 \\
\hline 16 & 1511.13 & 1511 & 1499 & 1512.46 & 1492.87 \\
\hline
\end{tabular}

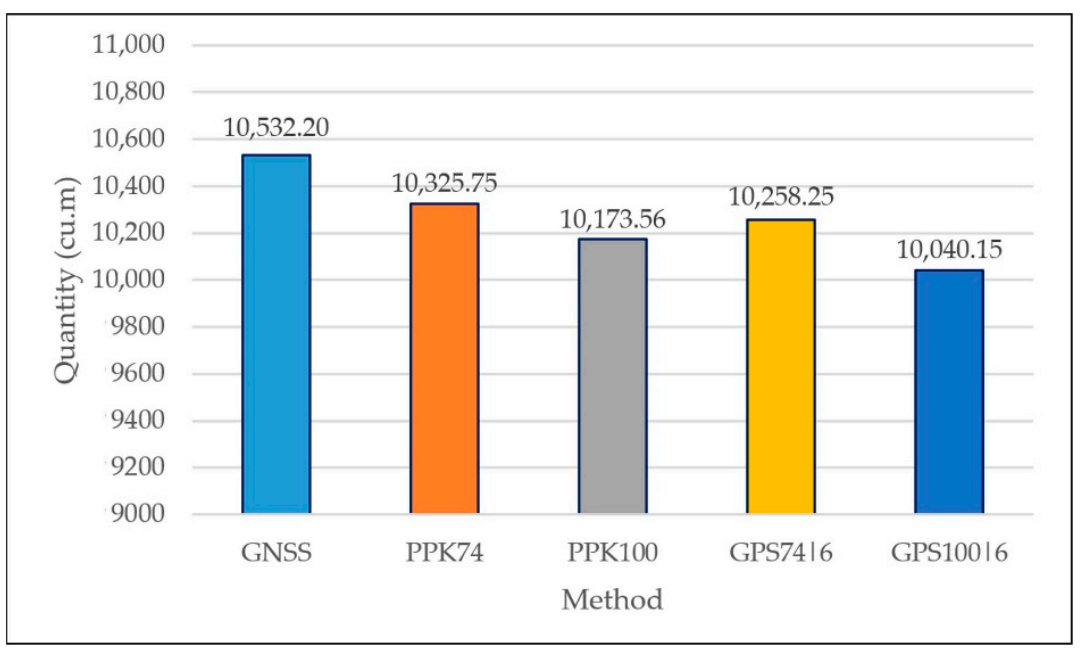

Figure 14. Total volume comparison of 16 stockpiles.

In some parts, the vegetation on stockpiles posed difficulties to make precise measurements from the defined boundaries. Therefore, additional estimations of five stockpiles were performed, with no obstructions, and the results obtained were included alongside the RTK survey results for comparison. The difference of volume calculation between the conventional and the UAV-based surveys was $1.96-4.67 \%$ and comparing between the UAV 
surveys- -0.22 to $2.76 \%$, and higher accuracy (1.08-2.12\%) was obtained acquiring images from $74 \mathrm{~m}$ height, which influenced the time of flight to last up to $54 \%$ longer and the amount of data to be captured $55 \%$ larger, compared to the $100 \mathrm{~m}$ flights. The quantities are provided in Table 6 . The smallest difference of $3.43 \%$ was obtained with PPK $74 \mathrm{~m}$ survey compared to the conventional approach. Visual results are shown in Figures 15 and 16.

Table 6. Comparison on 5 selected stockpiles volume calculations.

\begin{tabular}{|c|c|c|c|c|c|c|}
\hline \multirow{2}{*}{ Stockpile Number } & \multirow{2}{*}{$\begin{array}{c}\text { GNSS Receiver } \\
\text { Ground Level }\end{array}$} & \multicolumn{2}{|c|}{ PPK } & \multicolumn{2}{|c|}{6 GCPs-Based } & \multirow{2}{*}{$\begin{array}{c}\text { RTK } \\
100 \mathrm{~m} \text { Height }\end{array}$} \\
\hline & & $74 \mathrm{~m}$ Height & $100 \mathrm{~m}$ Height & $74 \mathrm{~m}$ Height & $100 \mathrm{~m}$ Height & \\
\hline 3 & 832.19 & 791 & 775 & 797.65 & 791.79 & 800.72 \\
\hline 9 & 242.96 & 239 & 236 & 236.13 & 229 & 237.29 \\
\hline 10 & 36.21 & 35.15 & 32.82 & 36.35 & 36 & 35.31 \\
\hline 15 & 1185.39 & 1101 & 1094 & 1060.42 & 1053.92 & 1068.88 \\
\hline 16 & 1511.13 & 1511 & 1499 & 1512.46 & 1492.87 & 1526.81 \\
\hline
\end{tabular}

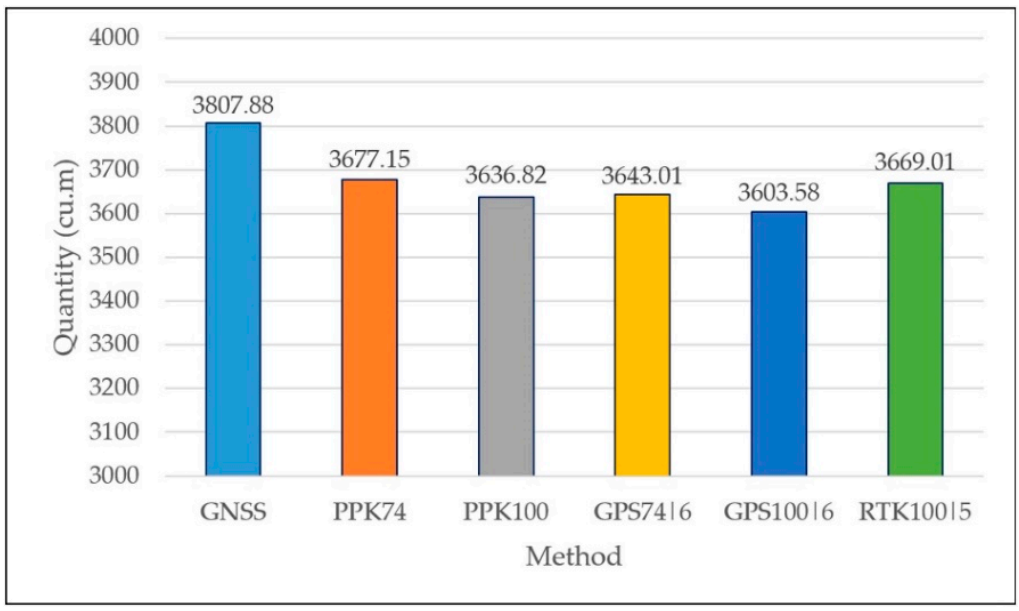

Figure 15. Volume comparison of 5 stockpiles.

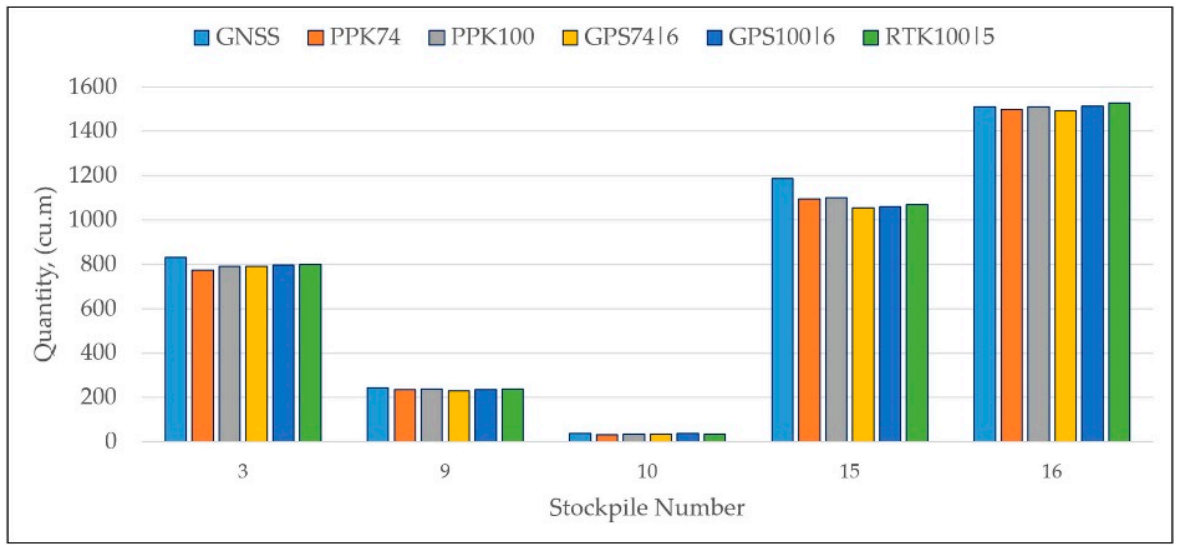

Figure 16. Visual volume comparison of 5 stockpiles.

\subsection{GCPs and Check Points Analysis}

The accuracy of the analyzed methods was evaluated by assessing the differences between the ground-surveyed markers and control points measured in photogrammetric models. Modern software, most adapted by the survey method was used, and the specificity of each software was not analyzed in detail. The deviation results were expressed in root mean square error (RMSE) values. As in real-life situations it is often not possible to place control points by using the correct scheme due to obstacles or moving traffic, 
some markers were placed on the edges of the surveyed area. The reason behind this placement was to analyze how each technique can cope with such irregularities of control point placement. PPK approach using Propeller AeroPoint markers as GPS recording base stations, was capable to use a one known point method. Primary results presented in Table 7 show that GCPs-based surveys with five and eight GCPs configurations were obtained with abnormal values and were therefore rejected from further investigation. Abnormal $Z$ values may have occurred for several reasons. One of them may be that five GCPs were not sufficient for an area of 36 ha when using GCPs-based approach. Depending on image resolution, the recommended ground control points to be spaced about 20,000 pixels from each other, which means that in our cases the distance between GCPs should be about $400 \mathrm{~m}$ when flying at $74 \mathrm{~m}$, and about $550 \mathrm{~m}$ when flying at $100 \mathrm{~m}$. However, the distances were less or about $400 \mathrm{~m}$. The reason for abnormal values could be insufficient number of GCPs. Inaccuracies in eight GCPs configuration could have occur because of a measurement mistake when determining the markers. If one of the measurements was not very precise, then more ground control points may give a negative result because the whole model can be deviated or turned. Additionally, in most cases, a checkpoint number 8 was obtained with an abnormal value. This happened because a checkpoint was at the edge of the mapping area and the accuracy was lost. This checkpoint was eliminated, and the results are shown in Table 8. Further, GCPs and CHPs were separated for inaccuracy analysis; five and eight GCPs configurations were dismissed from further analysis (Table 9). A table illustrating the GCPs and CHPs RMSE values for eleven points is provided in the Supplementary Materials (Table S7).

Table 7. Root mean square error (RMSE) values for 11 ground check points.

\begin{tabular}{cccc}
\hline Method & $\mathbf{X}(\mathbf{m})$ & $\mathbf{Y}(\mathbf{m})$ & $\mathbf{Z}(\mathbf{m})$ \\
\hline 1 known point PPK 74 m & 0.023 & 0.028 & 0.026 \\
1 known point PPK 100 m & 0.026 & 0.024 & 0.038 \\
6 GCPs-based GPS 74 m & 0.018 & 0.020 & 0.050 \\
6 GCPs-based GPS 100 m & 0.015 & 0.014 & 0.030 \\
5 GCPs-based GPS 74 m & 0.017 & 0.017 & 0.434 \\
5 GCPs-based GPS 100 m & 0.026 & 0.011 & 0.256 \\
8 GCPs-based GPS 74 m & 0.010 & 0.010 & 0.047 \\
8 GCPs-based GPS 100 m & 0.010 & 0.009 & 0.021 \\
\hline
\end{tabular}

Table 8. RMSE values for 10 points (with point number 8 eliminated).

\begin{tabular}{cccc}
\hline Method & $\mathbf{X}(\mathbf{m})$ & $\mathbf{Y}(\mathbf{m})$ & $\mathbf{Z}(\mathbf{m})$ \\
\hline 1 known point PPK 74 m & 0.023 & 0.029 & 0.026 \\
1 known point PPK 100 m & 0.027 & 0.020 & 0.033 \\
6 GCPs-based GPS 74 m & 0.018 & 0.012 & 0.020 \\
6 GCPs-based GPS 100 m & 0.015 & 0.014 & 0.026 \\
5 GCPs-based GPS 74 m & 0.007 & 0.018 & 0.297 \\
5 GCPs-based GPS 100 m & 0.026 & 0.012 & 0.222 \\
8 GCPs-based GPS 74 m & 0.011 & 0.009 & 0.049 \\
8 GCPs-based GPS 100 m & 0.010 & 0.005 & 0.021 \\
\hline
\end{tabular}

From the tables above, it can be seen that the PPK method shows reliable results with a total deviation, also separated from GCPs and CHPs. The accuracy of point number eight was not significantly affected either. The optimal configuration of GCPs-based survey in our case was with six GCPs and five check points. For further analysis, PPK and six GCPs-based datasets obtained at 74 and $100 \mathrm{~m}$, were evaluated. The results of these four datasets are shown in Figure 17. 
Table 9. Ground control points (GCPs) and check points (CHPs) RMSE values for 10 points (with Point number 8 eliminated).

\begin{tabular}{ccccccc}
\hline \multirow{2}{*}{ Method } & \multicolumn{3}{c}{ Ground Control Points } & \multicolumn{3}{c}{ Check Points } \\
\cline { 2 - 7 } & $\mathbf{X}(\mathbf{m})$ & $\mathbf{Y}(\mathbf{m})$ & $\mathbf{Z}(\mathbf{m})$ & $\mathbf{X ~ ( m )}$ & $\mathbf{Y ~ ( m ) ~}$ & $\mathbf{Z}(\mathbf{m})$ \\
\hline 1 known point PPK 74 m & 0.013 & 0.016 & 0.000 & 0.024 & 0.030 & 0.028 \\
1 known point PPK 100 m & 0.019 & 0.002 & 0.037 & 0.028 & 0.021 & 0.032 \\
6 GCPs-based GPS 74 m & 0.004 & 0.009 & 0.018 & 0.028 & 0.016 & 0.022 \\
6 GCPs-based GPS 100 m & 0.001 & 0.007 & 0.012 & 0.023 & 0.021 & 0.039 \\
5 GCPs-based GPS 74 m & 0.008 & 0.018 & 0.237 & 0.007 & 0.018 & 0.347 \\
5 GCPs-based GPS 100 m & 0.004 & 0.003 & 0.022 & 0.037 & 0.016 & 0.313 \\
8 GCPs-based GPS 74 m & 0.005 & 0.008 & 0.016 & 0.018 & 0.014 & 0.085 \\
8 GCPs-based GPS 100 m & 0.007 & 0.009 & 0.023 & 0.016 & 0.008 & 0.014 \\
\hline
\end{tabular}

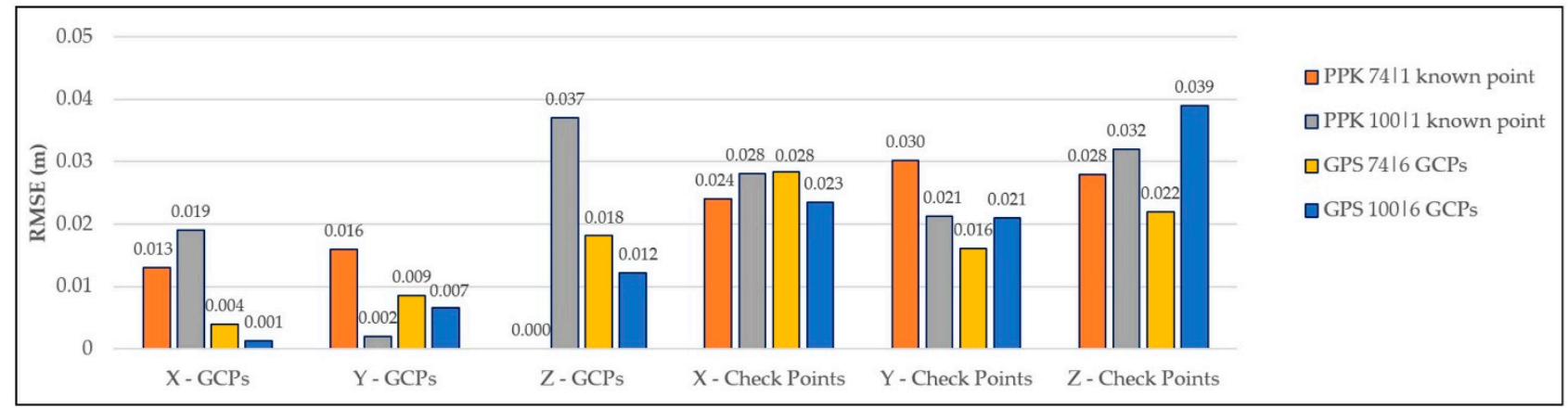

Figure 17. GCPs and CHPs root mean square error (RMSE) values of PPK and 6 GCPs-based GPS datasets.

In this analysis, the main focus was on the accuracy of the vertical datums. Using both survey methods, the datasets have a higher accuracy at GSD of $2.03 \mathrm{px} / \mathrm{cm}$ compared to $2.74 \mathrm{px} / \mathrm{cm}$. The effect of deviation according to GSD was significantly higher among GCPs-based datasets compared to the PPK method. In addition, a smaller-scale dataset with three and five GCPs configurations, obtained from $100 \mathrm{~m}$ height with the RTK function enabled, where seven control points were used. The results were promising (Table 10), but again, one check point at the edge of the survey area was used, which was later rejected due to the abnormal value obtained (Table 11).

Table 10. RTK and PPK RMSE values.

\begin{tabular}{cccc}
\hline Method & X (m) & Y (m) & Z (m) \\
\hline 3 GCPs-based RTK 100 m & 0.027 & 0.013 & 0.016 \\
5 GCPs-based RTK 100 m & 0.013 & 0.020 & 0.039 \\
1 known point PPK 100 m & 0.026 & 0.009 & 0.026 \\
\hline
\end{tabular}

Table 11. RTK and PPK RMSE values after removing one point.

\begin{tabular}{cccc}
\hline Method & X $(\mathbf{m})$ & Y (m) & Z (m) \\
\hline 3 GCPs-based RTK 100 m & 0.014 & 0.014 & 0.017 \\
5 GCPs-based RTK 100 m & 0.013 & 0.009 & 0.017 \\
1 known point PPK 100 m & 0.026 & 0.009 & 0.026 \\
\hline
\end{tabular}

A 100-m-height PPK survey was additionally performed with five control points under winter conditions for the observation of the influence of weathering. In this case only one ground control point was used for processing. Additional visual results of the smaller-scale RTK and PPK study are presented in Figure 18. GCPs and CHPs separated RMSE values presented in Table 12 and Figure 19. 


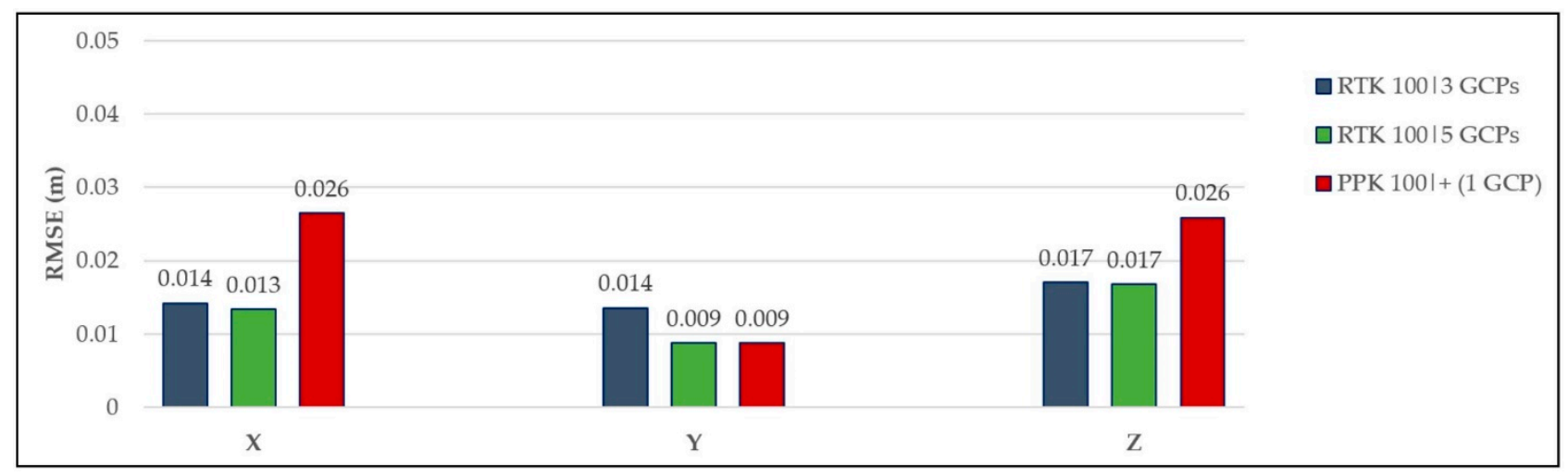

Figure 18. RTK and PPK surveys results (smaller scale).

Table 12. PPK and RTK surveys GCPs and CHPs RMSE results.

\begin{tabular}{ccccccc}
\hline \multirow{2}{*}{ Method. } & \multicolumn{3}{c}{ Ground Control Points } & \multicolumn{3}{c}{ Check Points } \\
\cline { 2 - 7 } & $\mathbf{X}(\mathbf{m})$ & $\mathbf{Y ~ ( m )}$ & $\mathbf{Z ~ ( m )}$ & $\mathbf{X ~ ( m )}$ & $\mathbf{Y ~ ( m ) ~}$ & $\mathbf{Z}(\mathbf{m})$ \\
\hline 3 GCPs-based RTK 100 m & 0.008 & 0.012 & 0.010 & 0.018 & 0.015 & 0.021 \\
5 GCPs-based RTK 100 m & 0.006 & 0.009 & 0.019 & 0.023 & 0.008 & 0.009 \\
1 known point PPK 100 m & 0.013 & 0.014 & 0.013 & 0.029 & 0.007 & 0.028 \\
\hline
\end{tabular}

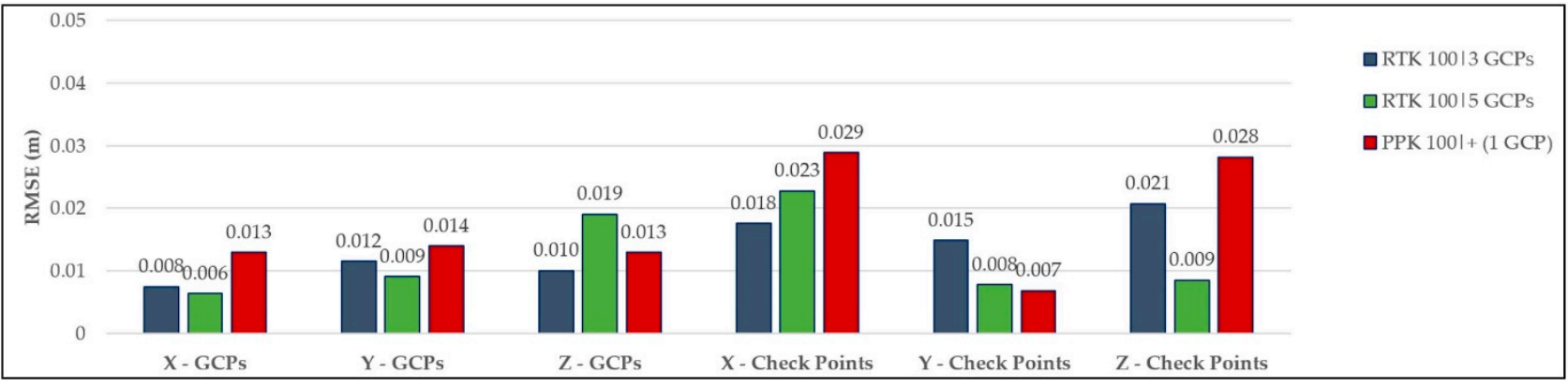

Figure 19. PPK and RTK surveys GCPs and CHPs RMSE results.

Summarized vertical datums results between all methods provided in Figure 20. The best accuracy in our case was obtained using UAV-based photogrammetric survey with RTK enabled three and five GCPs configurations, but when the GCPs and CHPs were separated the difference between the configurations was significant. With PPK and GCPsbased surveys similar accuracy of vertical datums was achieved. It should be emphasized that to achieve that accuracy with GCPs-based survey method we were forced to dismiss five GCPs configuration dataset because it contained abnormal values of check points and eight GCPs configuration dataset as the results were inaccurate, and additionally to remove one control point which was at the edge of the survey area. It should also be noted that UAV-based RTK surveys were not accomplished fully as planned because the RTK signal was lost during the survey. In this study the results from PPK survey were proven to be the most reliable and performance efficient with reasonable and stable accuracy. The difference between PPK general Z accuracy and check points accuracy in all cases was insignificant. Only one known point method was used, and it coped well with the point at the edge of the survey area while other methods had issues. By removing the point out of the dataset, the results were very slightly affected.

In Figure 21 we presented the comparison of vertical datums comparison of each point separately without elimination of the extreme points (Tables S8-S11 in the Supplementary Materials provide a detailed analysis). The extreme points were considered number 10 in the RTK dataset and number eight in all other datasets. There was one extreme point with 
abnormal value from one of two datasets or configurations in the surveys for each method. Six GCPs configuration dataset demonstrated the highest deviation of the particular point. RTK dataset showed the best result of the extreme point accuracy when it was processed using the three GCPs configuration but the abnormal result was obtained with five GCPs configuration, which affected a high contrast between those two cases. Due to this contrast, it can be argued that the results at this point may be not very stable. In PPK approach the discussed point obtained most reliable results. Although in one of the cases the point was deviated at $0.073 \mathrm{~m}$, it nevertheless demonstrated the highest accuracy comparing to other abnormal endpoint values, and the contrast between to datasets was insignificant.

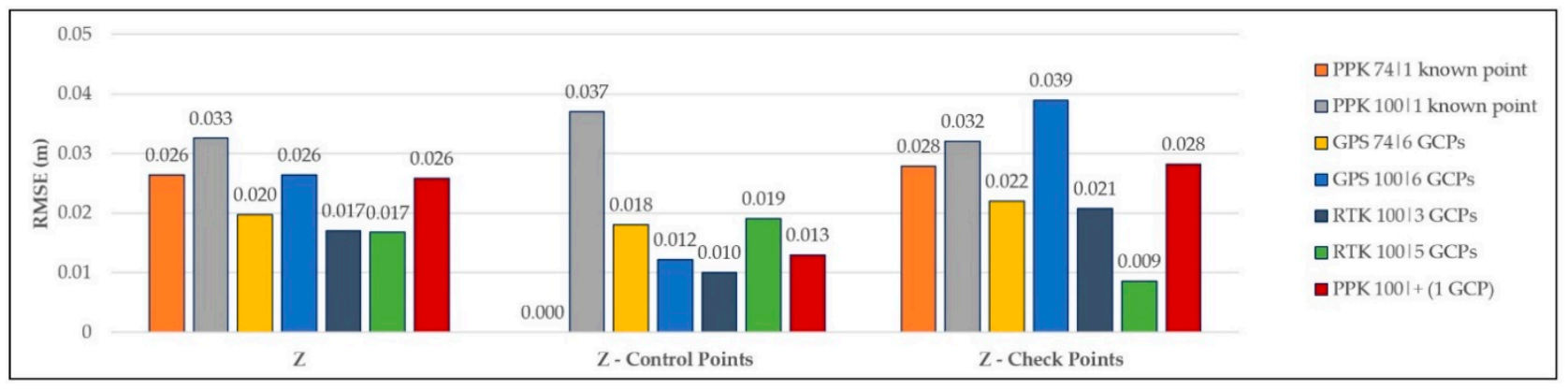

Figure 20. Summary of vertical datums results between all analyzed methods.

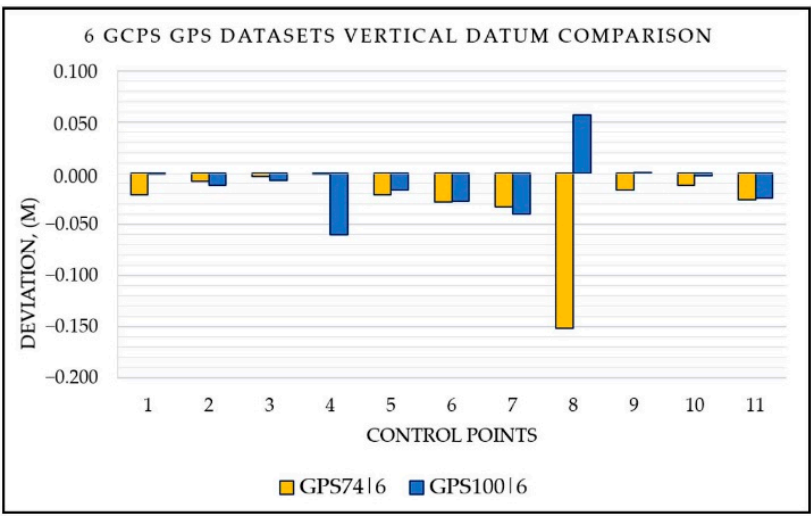

(a)

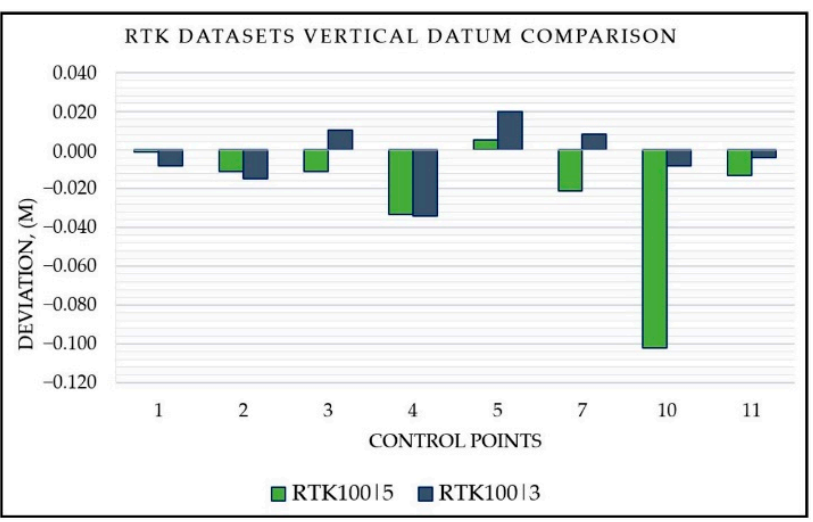

(c)

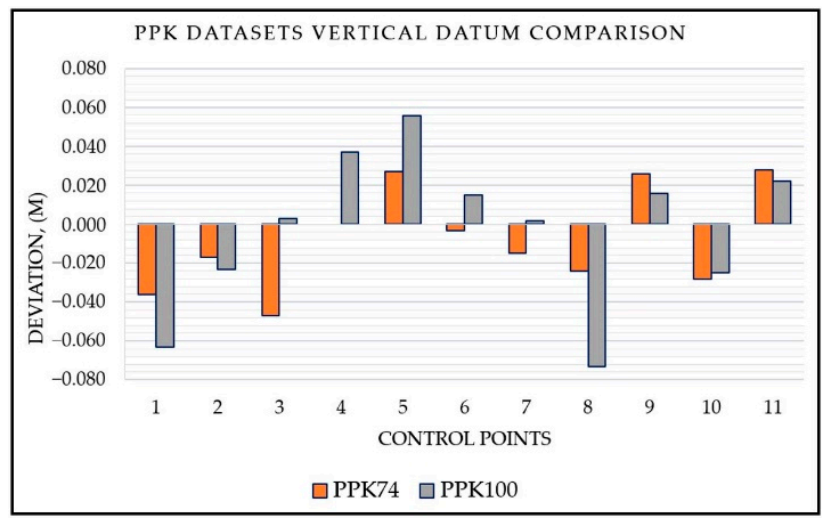

(b)

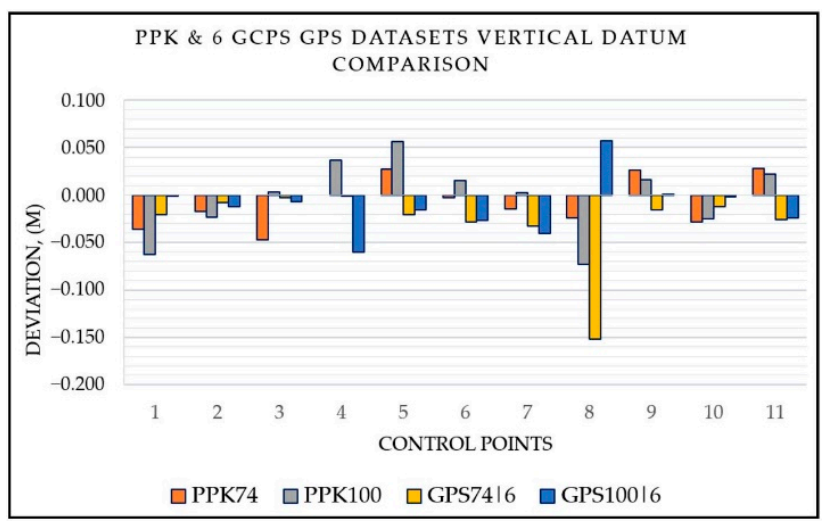

(d)

Figure 21. Vertical control points analysis: (a) 6 GCPs-based GPS datasets, (b) 1 known point PPK datasets, (c) 3 and 6 GCPs-based RTK dataset, and (d) vertical datum comparison of PPK and 6 GCPs-based GPS datasets. 
In our case, comparing the volume results and cross-sections of stockpiles, it can be stated that conventional measurements with a GNSS receiver were less accurate than measurements using UAV-based photogrammetric techniques. This is because manual measurements result in much fewer points. The $100 \mathrm{~m}$ flight took $54 \%$ less time and acquired $55 \%$ less data compared to $74 \mathrm{~m}$ flight. With photogrammetric measurements of more than 10,000 cubic meters of earth, the GSD affected the results by 1.08 to $2.12 \%$, depending on the method. PPK and RTK methods showed the best efficiency because only one or few control points were needed, but RTK also showed a limitation due to in-flight loss of RTK signal.

Further research activities can be considered in several directions. Currently more advanced Propeller AeroPoints 2.0 showed up in the industry. Their accuracy has not yet been tested. A similar accuracy assessment could be performed on a real, busy construction site. Another area of research could be how one or more inaccurate measurements of ground control points can affect the digital model accuracy in various software packages.

\subsection{Limitations}

Using GCPs-based method, the calculation is made that the images are stitched together incorporating the data from the ground control points. Camera positions are calculated first, which can be a source of inaccuracy. This method can be not so accurate between the points, the bigger the distance between the GCPs, the bigger inaccuracy. To avoid inaccuracies in GCPs-based method it is important to place a sufficient amount ground control points by using a correct placement scheme. Depending on image resolution, the recommended ground control points to be spaced about 20,000 pixels from each other. RTK calculation goes through the camera positions and is corrected in real time, but when there are gaps in signal, either the correction signal or GNSS, it will have error and there is no way to correct it afterwards. The blocking of the signal happens all the time, for example trees, buildings, etc. Signal loss creates unreliability. When using PPK workflow, the images are not geotagged right away with the correction. The correction is calculated after there is available real satellite geometry, that means that all gaps or errors in satellite geometry will be corrected, and when there are gaps in signals, they can be filled afterwards by PPK calculations. In this way we get more accurate geotags in the images. In PPK method with AeroPoints all errors are documented. Another reason for PPK method reliability is that AeroPoints are used as GCPs, so the point tunning after the geotags does not correct the point tunning of the absolute position. XYZ position for ground surface is corrected by using the known point. That makes it more reliable. All errors in camera angle, and in drone itself measuring the angle and lens will be calibrated this way. Other limitation when using PPK method with AeroPoints 1.0 is that a UAV has to be at least $10 \mathrm{~min}$ in the mission mode in the air. If a very short flight has to be performed it is recommended to pause the flight and hover in the air for a total flight time of $10 \mathrm{~min}$. AeroPoints 1.0 have to be placed on the ground in order to collect enough GPS data for at least 45 min which is another limitation for short flights and can reduce an efficiency. General in photogrammetry the high contrast shadows of tall trees or buildings can have a significant effect on accuracy, especially when using linear flights, the ground has time rotate, so high-contrast shadows shift slightly to another position in overlapping images, which can lead to an irregular surface in the final result.

\section{Conclusions}

A 36 ha quarry was surveyed by two separate DJI Phantom 4 RTKs and one DJI Phantom 4 Pro UAV. Three different UAV-based photogrammetry methods were compared and described: PPK, RTK, and GCPs-based. Sixteen stockpiles with a volume of more than ten thousand cubic meters were measured using a conventional method with Trimble SPS985 GNSS receiver for comparison with UAV-based survey techniques. A set of ground control points was measured and used to evaluate the accuracy of the reality mesh model. Survey datasets were processed and analyzed using modern desktop software tools and cloud 
platform: ContextCapture, Descartes, Trimble Stratus powered by Propeller. In addition, the innovative use of PPK technology used in conjunction with Propeller markers used as GPS data recording base stations and used with one known point method has been analyzed and described.

The difference between the photogrammetrically obtained stockpiles volume was compared between the conventional GNSS approach and between different UAV-based calculation results. In all cases, the volume was lower compared to a survey conducted manually using a GNSS receiver. Residuals between photogrammetrically obtained reality mesh coordinates were compared and analyzed with field-determined markers. The results of the PPK and RTK approaches were good depending on the GSD value. The accuracy of the model obtained by the GCPs-based method was significantly influenced by the number of control points. Using all methods, some anomalous residuals were obtained at the edge of the mapping area, but the most significant deviation was found using the GCPs-based approach.

Supplementary Materials: The following are available online at https:/ /www.mdpi.com/article/10 .3390/ijgi10060399/s1, Table S1: Control points measurement information. UAV-based PPK method. Table S2: Control points measurement information. UAV 5 GCPs-based method. Table S3: Control points measurement information. UAV 6 GCPs-based method. Table S4: Control points measurement information. UAV 8 GCPs-based method. Table S5: Control points measurement information. UAV GCPs-based RTK method. Table S6: Control points measurement information for smaller-scale PPK survey. Separate measurements were obtained using GNSS receiver. Table S7: RMSE values for 11 control points. Table S8: Vertical reference point differences obtained through manual GNSS and UAV-based PPK methods. Table S9: Differences in vertical reference points obtained using ground level manual GNSS and $74 \mathrm{~m}$ UAV GCPs-based methods. Table S10: Differences in vertical reference points obtained using ground level manual GNSS and $100 \mathrm{~m}$ UAV GCPs-based methods. Table S11: Vertical reference point differences in smaller-scale RTK/PPK surveys. Figure S1: Example of the boundaries used for stockpiles volume comparison. Stockpile number 3. Figure S2: Example of the boundaries used for stockpiles volume comparison. Stockpile number 15. Figure S3: Example of the boundaries used for stockpiles volume comparison. Stockpile number 16.

Author Contributions: Conceptualization, Paulius Kavaliauskas and Andrius Jurelionis; methodology, Paulius Kavaliauskas, Andrius Jurelionis and Daumantas Židanavičius; data acquisition in the survey site, Paulius Kavaliauskas and Daumantas Židanavičius; post-processing and software tools, Paulius Kavaliauskas; validation, Paulius Kavaliauskas; investigation, Paulius Kavaliauskas; writing—-review and editing, Paulius Kavaliauskas and Andrius Jurelionis; visualization, Paulius Kavaliauskas; supervision, Andrius Jurelionis; All authors have read and agreed to the published version of the manuscript.

Funding: This research received no external funding.

Institutional Review Board Statement: Not applicable.

Informed Consent Statement: Not applicable.

Acknowledgments: The authors express their gratitude to YIT Lietuva and Bentley Systems for providing the access to the site, technical equipment, software and guidance on digital workflows.

Conflicts of Interest: The authors declare no conflict of interest.

\section{References}

1. Sanhudo, L.; Ramos, N.M.M.; Martins, J.P.; Almeida, M.S.F.; Barreira, E.; Simoes, M.L.; Cardoso, V. A framework for in-situ geometric data acquisition using laser scanning for BIM modelling. J. Build. Eng. 2020, 28, 101073. [CrossRef]

2. Shao, J.; Zhang, W.; Mellado, N.; Wang, N.; Jin, S.; Cai, S.; Luo, L.; Lejemble, T.; Yan, G. SLAM-aided forest plot mapping combining terrestrial and mobile laser scanning. ISPRS J. Photogramm. Remote Sens. 2020, 163, 214-230. [CrossRef]

3. Hosseininaveh, A.A.; Sargeant, B.; Erfani, T.; Robson, S.; Shortis, M.; Hess, M.; Boehm, J. Towards fully automatic reliable 3D acquisition: From designing imaging network to a complete and accurate point cloud. Robot. Auton. Syst. 2014, 62, 1197-1207. [CrossRef]

4. Zhang, X.; Zhao, P.; Hu, Q.; Ai, M.; Hu, D.; Li, J. A UAV-based panoramic oblique photogrammetry (POP) approach using spherical projection. ISPRS J. Photogramm. Remote Sens. 2020, 159, 198-219. [CrossRef] 
5. Saadati, S.; Abbasi, M.; Abbasy, S.; Amiri-Simkooei, A. Geodetic calibration network for total stations and GNSS receivers in sub-kilometer distances with sub-millimeter precision. Measurement 2019, 141, 258-266. [CrossRef]

6. Lutz, K. 61-years of working aerial photogrammetry history. Photogramm. Eng. Remote Sens. 2015, 81, 89-93. [CrossRef]

7. Bang, S.; Kim, H. Context-based information generation for managing UAV-acquired data using image captioning. Autom. Constr. 2020, 112, 103116. [CrossRef]

8. Omar, H.; Mahdjoubi, L.; Khedar, G. Towards an automated photogrammetry-based approach for monitoring and controlling construction site activities. Comput. Ind. 2018, 98, 172-182. [CrossRef]

9. Braun, A.; Borrmann, A. Combining inverse photogrammetry and BIM for automated labeling of construction site images for machine learning. Autom. Constr. 2019, 106, 102879. [CrossRef]

10. Wang, C.; Cho, Y.K.; Kim, C. Automatic BIM component extraction from point clouds of existing buildings for sustainability applications. Autom. Constr. 2015, 56, 1-13. [CrossRef]

11. Poux, F.; Mattes, C.; Kobbelt, L. Unsupervised segmentation of indoor 3D point cloud: Application to object-based classification. Int. Arch. Photogramm. Remote Sens. Spatial Inf. Sci. 2020, 44, 111-118. [CrossRef]

12. Unger, J.; Reich, M.; Heipke, C. UAV-based photogrammetry: Monitoring of a building zone. Int. Arch. Photogramm. Remote. Sens. Spat. Inf. Sci. ISPRS Arch. 2014, 40, 601-606. [CrossRef]

13. Jones, C.A.; Church, E. Photogrammetry is for everyone: Structure-from-motion software user experience in archaeology. J. Archaeol. Sci. Rep. 2020, 30, 102261. [CrossRef]

14. Ferraby, R.; Powlesland, D. Heritage and landscape change: Recording, archiving and engaging with photogrammetry on the Jurassic World heritage Site. Proc. Geol. Assoc. 2019, 130, 483-492. [CrossRef]

15. O'Driscoll, J. Landscape applications of photogrammetry using unmanned aerial vehicles. J. Archaeol. Sci. Rep. 2018, 22, 32-44. [CrossRef]

16. Du, J.-C.; Teng, H.-C. 3D laser scanning and GPS technology for landslide earthwork volume estimation. Autom. Constr. 2007, 16, 657-663. [CrossRef]

17. Kwon, S.; Park, J.-W.; Moon, D.; Jung, S.; Park, H. Smart merging method for hybrid point cloud data using UAV and LIDAR in earthwork construction. Procedia Eng. 2017, 196, 21-28. [CrossRef]

18. Freimuth, H.; Konig, M. Planning and executing construction inspections with unmanned aerial vehicles. Autom. Constr. 2018, 96, 540-553. [CrossRef]

19. Siebert, S.; Teizer, J. Mobile 3D mapping for surveying earthwork projects using an Unmanned Aerial Vehicle (UAV) system. Autom. Constr. 2014, 41,1-14. [CrossRef]

20. Kamari, M.; Ham, Y. Vision-based volumetric measurements via deep learning-based point cloud segmentation for material management in jobsites. Autom. Constr. 2021, 121, 103430. [CrossRef]

21. Moon, D.; Chung, S.; Kwon, S.; Seo, J.; Shin, J. Comparison and utilization of point cloud generated from photogrammetry and laser scanning: 3D world model for smart heavy equipment planning. Autom. Constr. 2019, 98, 322-331. [CrossRef]

22. Hellmuth, R.; Wehner, F.; Giannakidis, A. Datasets of captured images of three different devices for photogrammetry calculation comparison and integration into laser scan point cloud of a built environment. Data Brief 2020, 33, 106321. [CrossRef]

23. Casella, V.; Chiabrando, F.; Franzini, M.; Manzino, A.M. Accuracy assessment of a UAV block by different software packages, processing schemes and validation strategies. ISPRS Int. J. GeoInf. 2020, 9, 164. [CrossRef]

24. Martínez-Carricondo, P.; Agüera-Vega, F.; Carvajal-Ramírez, F.; Mesas-Carrascosa, F.J.; García-Ferrer, A.; Pérez-Porras, F.J. Assessment of UAV-photogrammetric mapping accuracy based on variation of ground control points. Int. J. Appl. Earth Obs. Geoinf. 2018, 72, 1-10. [CrossRef]

25. Akturk, E.; Altunel, A.O. Accuracy assessment of a low-cost UAV derived digital elevation model (DEM) in a highly broken and vegetated terrain. Measurement 2019, 136, 382-384. [CrossRef]

26. Cryderman, C.; Mah, S.B.; Shufletoski, A. Evaluation of UAV photogrammetric accuracy for mapping and earthworks computations. Geomatica 2014, 68, 209-317. [CrossRef]

27. Nocerino, E.; Menna, F.; Remondino, F.; Saleri, R. Accuracy and Block Deformation Analysis in Automatic UAV and Terrestrial Photogrammetry-Lesson Learnt. In Proceedings of the ISPRS Annals of the Photogrammetry, Remote Sensing and Spatial Information Sciences, Volume II-5/W1, 2013 XXIV International CIPA Symposium, Strasbourg, France, 2-6 September 2013.

28. Sanz-Ablanedo, E.; Chandler, H.J.; Rodriguez-Perez, J.R.; Ordonez, C. Accuracy of unmanned aerial vehicle (UAV) and SFM photogrammetry survey as a function of the number and location of ground control points used. Remote Sens. 2018, 10, 1606. [CrossRef]

29. Tahar, K.N. An Evaluation on Different Number of Ground Control Points in Unmanned Aerial Vehicle Photogrammetric Block. In Proceedings of the International Archives of the Photogrammetry, Remote Sensing and Spatial Information Sciences, Volume XL-2/W2, ISPRS 8th 3DGeoInfo Conference \& WG II/2 Workshop, Istanbul, Turkey, 27-29 November 2013.

30. Yang, B.; Ali, F.; Yin, P.; Yang, T.; Yu, Y.; Li, S.; Liu, X. Approaches for exploration of improving multi-slice mapping via forwarding intersection based on images of UAV oblique photogrammetry. Comput. Electr. Eng. 2021, 92, 107135. [CrossRef]

31. O'Connor, J.; Smith, M.; James, R.M. Impact of image compression on structure from motion photogrammetry. Geophys. Res. Abstr. 2019, 21, EGU2019-EGU15523.

32. Alfio, S.V.; Costantino, D.; Pepe, M. Influence of image TIFF format and JPEG compression level in the accuracy of the 3D model and quality of the orthophoto in UAV photogrammetry. J. Imaging 2020, 6, 30. [CrossRef] 
33. Dandois, J.P.; Olano, M.; Ellis, E.C. Optimal altitude, overlap, and weather conditions for computer vision UAV estimates of forest structure. Remote Sens. 2015, 7, 13895-13920. [CrossRef]

34. Bemis, S.P.; Micklethwaite, S.; Turner, D.; James, M.R.; Akciz, S.; Thiele, S.T.; Bangash, H.A. Ground-based and UAV-based photogrammetry: A multi-scale, high-resolution mapping tool for structural geology and paleoseismology. J. Struct. Geol. 2014, 69, 163-178. [CrossRef]

35. Hill, A.C. Economical drone mapping for archaeology: Comparison of efficiency and accuracy. J. Archaeol. Sci. Rep. 2019, 24, 80-91. [CrossRef]

36. Cledat, E.; Jospin, L.V.; Cucci, D.A.; Skaloud, J. Mapping quality prediction for RTK/PPK-equipped micro-drones operating in complex natural environment. ISPRS J. Photogramm. Remote Sens. 2020, 167, 24-38. [CrossRef]

37. Taddia, Y.; Stecchi, F.; Pellegrinelli, A. Coastal mapping using DJI phantom 4 RTK in post-processing kinematic mode. Drones 2020, 4, 9. [CrossRef]

38. Tomastik, J.; Mokros, M.; Surovy, P.; Grznarova, A.; Merganic, J. UAV RTK/PPK method—An optimal solution for mapping inaccessible forested areas. Remote Sens. 2019, 11, 721. [CrossRef]

39. Stroner, M.; Urban, R.; Seidl, J.; Reindl, T.; Broucek, J. Photogrammetry using UAV-mounted GNSS RTK: Georeferencing strategies without GCPs. Remote Sens. 2021, 13, 1336. [CrossRef]

40. Dardanelli, G.; Maltese, A.; Pipitone, C.; Pisiciotta, A.; Brutto, M.L. NRTK, PPP or static, that is the question. Testing different positioning solutions for GNSS survey. Remote Sens. 2021, 13, 1406. [CrossRef]

41. James, M.R.; Robson, S.; d'Oleire-Oltmanns, S.; Niethammer, U. Optimising UAV topographic surveys processed with structurefrom-motion: Ground control quality, quantity and bundle adjustment. Geomorphology 2017, 280, 51-66. [CrossRef]

42. Sun, P.; Zhou, F.; Sun, J.; Wang, L. High-accuracy three-dimensional measurement based on multi-directional cooperative target with weighted SfM algorithm. Measurement 2021, 172, 108955. [CrossRef]

43. Wang, R.; Lin, J.; Li, L.; Xiao, Z.; Hui, Y.; Xin, Y. A revised orientation-based correction method for SfM-MVS point clouds of outcrops using ground control planes with marks. J. Struct. Geol. 2021, 143, 104266. [CrossRef]

44. Lewinska, P.; Galas, A. Use of structure-from-motion algorithms for geomorphological analyses of simple volcanic structures: A case study of Chilcayoc Chico and four other volcanoes of the Andahua Group, Peru. J. South Am. Earth Sci. 2021, 107, 103058. [CrossRef]

45. Westoby, M.J.; Brasington, J.; Glasser, N.F.; Hambrey, M.J.; Reynolds, J.M. 'Structure-from-Motion' photogrammetry: A low-cost, effective tool for geoscience applications. Geomorphology 2012, 179, 300-314. [CrossRef]

46. Xiong, B.; Li, X. Offset measurements along active faults based on the structure from motion method-A case study of Gebiling in the Xorkoli section of the Altyn Tagh Fault. Geod. Geodyn. 2020, 11, 358-366. [CrossRef]

47. Parseliunas, E.; Buga, A.; Marozas, L.; Petniunas, M.; Urbanas, S. Litpos-A part of EUPOS. Geod. Cartogr. $2008,34,50-57$. [CrossRef]

48. Hastaoglu, K.O.; Gull, Y.; Poyraz, F.; Kara, B.C. Monitoring 3D areal displacements by a new methodology and software using UAV photogrammetry. Int. J. Appl. Earth Obs. Geoinf. 2019, 83, 101916. [CrossRef]

49. Forlani, G.; Dall'Asta, E.; Diotri, F.; Cella, U.M.D.; Roncella, R.; Santise, M. Quality assessment of DSMs produced from UAV flights georeferenced with on-board RTK positioning. Remote Sens. 2018, 10, 311. [CrossRef]

50. Lewinska, P.; Glowacki, O.; Moskalik, M.; Smith, W.A.P. Evaluation of structure-from-motion for analysis of small-scale glacier dynamics. Measurement 2021, 168, 108327. [CrossRef]

51. Kingsland, K. Comparative analysis of digital photogrammetry software for cultural heritage. Digit. Appl. Archaeol. Cult. Herit. 2020, 18, e001557. [CrossRef] 